U.S.
ARTMENT
OF
OMMERCE

National QC au 100 ds 5753 0.792 1973 c. 
The National Bureau of Standards ${ }^{1}$ was established by an act of Congress March 3, 1901. The Bureau's overall goal is to strengthen and advance the Nation's science and technology and facilitate their effective application for public benefit. To this end, the Bureau conducts research and provides: (1) a basis for the Nation's physical measurement system, (2) scientific and technological services for industry and government, (3) a technical basis for equity in trade, and (4) technical services to promote public safety. The Bureau consists of the Institute for Basic Standards, the Institute for Materials Research, the Institute for Applied Technology, the Institute for Computer Sciences and Technology, and the Office for Information Programs.

THE INSTITUTE FOR BASIC STANDARDS provides the central basis within the United States of a complete and consistent system of physical measurement; coordinates that system with measurement systems of other nations; and furnishes essential services leading to accurate and uniform physical measurements throughout the Nation's scientific community, industry, and commerce. The Institute consists of a Center for Radiation Research, an Office of Measurement Services and the following divisions:

Applied Mathematics - Electricity - Mechanics - Heat - Optical Physics - Nuclear Sciences ${ }^{2}$ - Applied Radiation ${ }^{2}$ - Quantum Electronics ${ }^{3}$ — Electromagnetics ${ }^{3}$ — Time and Frequency ${ }^{3}$ - Laboratory Astrophysics ${ }^{3}$ - Cryogenics ${ }^{3}$.

THE INSTITUTE FOR MATERIALS RESEARCH conducts materials research leading to improved methods of measurement, standards, and data on the properties of well-characterized materials needed by industry, commerce, educational institutions, and Government; provides advisory and research services to other Government agencies; and develops, produces, and distributes standard reference materials. The Institute consists of the Office of Standard Reference Materials and the following divisions:

Analytical Chemistry - Polymers - Metallurgy - Inorganic Materials - Reactor Radiation - Physical Chemistry.

THE INSTITUTE FOR APPLIED TECHNOLOGY provides technical services to promote the use of available technology and to facilitate technological innovation in industry and Government; cooperates with public and private organizations leading to the development of technological standards (including mandatory safety standards), codes and methods of test; and provides technical advice and services to Government agencies upon request. The Institute consists of a Center for Building Technology and the following divisions and offices:

Engineering and Product Standards - Weights and Measures - Invention and Innovation - Product Evaluation Technology - Electronic Technology - Technical Analysis - Measurement Engineering — Structures, Materials, and Life Safety “ — Building Environment ${ }^{4}$ - Technical Evaluation and Application ${ }^{4}$ - Fire Technology.

THE INSTITUTE FOR COMPUTER SCIENCES AND TECHNOLOGY conducts research and provides technical services designed to aid Government agencies in improving cost effectiveness in the conduct of their programs through the selection, acquisition, and effective utilization of automatic data processing equipment; and serves as the principal focus within the executive branch for the development of Federal standards for automatic data processing equipment, techniques, and computer languages. The Center consists of the following offices and divisions:

Information Processing Standards - Computer Information - Computer Services Systems Development - Information Processing Technology.

THE OFFICE FOR INFORMATION PROGRAMS promotes optimum dissemination and accessibility of scientific information generated within NBS and other agencies of the Federal Government; promotes the development of the National Standard Reference Data System and a system of information analysis centers dealing with the broader aspects of the National Measurement System; provides appropriate services to ensure that the NBS staff has optimum accessibility to the scientific information of the world. The Office consists of the following organizational units:

Office of Standard Reference Data - Office of Technical Information and Publications Library — Office of International Relations.

\footnotetext{
${ }^{1}$ Headquarters and Laboratories at Gaithersburg, Maryland, unless otherwise noted; mailing address Washington, D.C. 20234.

'Part of the Center for Radiation Research.

Located at Boulder, Colorado $\mathbf{8 0 3 0 2 .}$

4 Part of the Center for Building Technology.
} 


\section{Investigation of Viscous Flow in Glass During Phase Separation}

Joseph H. Simmons, Susan A. Mills, Albert Napolitano, Douglas H. Blackburn, and Wolfgang K. Haller

Inorganic Materials Division Institute for Materials Research National Bureau of Standards Washington, D.C. 20234

Sponsored by:

The Office of Naval Research

Contract Naonr 12-73, NR 032-536

Department of the Navy

Code 471, Washington, D.C. 20360

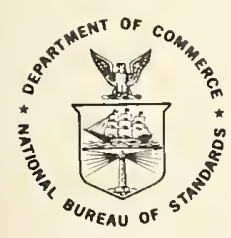

U.S. DEPARTMENT OF COMMERCE, Frederick B. Dent, Secrefary NATIONAL BUREAU OF STANDARDS, Richard W. Roberts, Director 
National Bureau of Standards Technical Note 792

Nat. Bur. Stand. (U.S.), Tech. Note 792, 43 pages (Sept. 1973) CODEN: NBTNAE

For sale by the Superintendent of Documents, U.S. Government Printing Office, Washington, D.C. 20402 (Order by SD Catalog No. C13.46:792). Price $\$ 0.65$ 
TABLE OF CONTENTS

Page

1. Introduction $\ldots \ldots \ldots \ldots \ldots \ldots \ldots \ldots \ldots \ldots \ldots$

2. Experimental Section ................... 3

2.1 Microstructure Measurement ............ 3

2.2 Viscosity Measurement ............... 9

3. Results and Discussion ................... 13

3.1 Analysis of Microstructure Growth ........ 13

3.2 Analysis of Viscosity Change ............ 15

3.3 Formulation of Viscosity Change ......... 26

4. Conclusions ........................ 33

5. References ........................ 36 

Investigation of Viscous Flow in Glass During Phase Separation

Joseph H. Simmons, Susan A. Mills, Albert Napolitano Douglas $\mathrm{H}$. Blackburn and Wolfgang $\mathrm{K}$. Haller

The isothermal viscosity of two borosilicate glasses, of which one is a commercial glass widely used for chemical glassware, shows a large increase ( 4 to 5 orders of magnitude) with heat-treatment time (ranging up to $100,000 \mathrm{~min}$ ) near the annealing point. The two glasses have similar compositions, but differ greatly in their phase separation characteristics. Electron micrographs are used to analyze the development of microstructure during the suspected phase separation. In both glasses, it is found that the structure development is primarily responsible for the viscosity increase. An analysis of the data, and a theoretical interpretation of the effect are presented.

Key words: Glass; microstructure; phase separation; viscosity.

\section{Introduction}

The study of viscosity during liquid-liquid phase transitions in glasses offers a promising means of investigating the effect of microstructure on viscous flow processes. While recent measurements of viscosity and other properties $[1,2]^{1 /}$ have strongly indicated the presence of microstructure in some non-phase separating glasses, attempts to detect or measure this structure have generally yielded negative or conflicting results [3-5]. Conversely, microstructure arising from liquid-liquid phase transitions can generally be analyzed by electron microscopy [6] and its size may readily be selected within wide ranges by suitable heat-treatments. Further, analytical work conducted at this laboratory on results from ultrasonic relaxation measurements on oxide glass mixtures above the phase transition temperature [7] If Figures in brackets indicate the literature references at the end of this paper. 
have suggested that the interaction of microstructure with viscous flow processes depends only upon the activation energy differences between the phases. Therefore, it is expected that results obtained on phase separated glasses can be extended to glasses with microstructure of a different nature.

We present, here, results from an investigation of the change in viscosity behavior of two oxide glasses, resulting from a developing phase separation. These glasses were chosen with basically equivalent compositions but different immiscibility behavior.

The first is a model glass for immiscibility studies with a composition of $\mathrm{SiO}_{2}, \mathrm{~B}_{2} \mathrm{O}_{3}$ and $\mathrm{Na}_{2} \mathrm{O}$ in the proportions: 70:23:7 by weight (hence known as Type I). Its phase-transition temperature $\left(755^{\circ} \mathrm{C}\right.$ ) occurs near the maximum of the immiscibility surface for the system (Sample 42 in Ref. 8). Consequently, the viscosity is $10 \mathrm{w}\left(10^{7}\right.$ poises) at the phase-transition temperature (see fig. 1) [9] and the glass

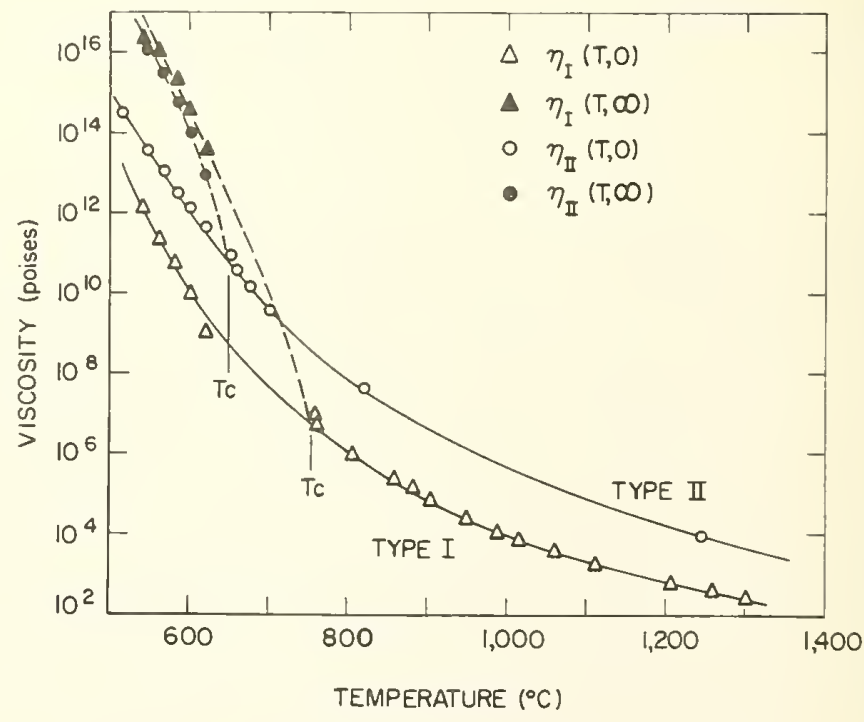

Fig. 1. Viscosity curves for glasses of Type I and II. $\eta(T, O)$ is the viscosity of the single phase glass (prior to immiscibility), and $n(T, \infty)$ is the viscosity of the totally phase separated glass. 
readily displays very evident phase separation characteristics. Its microstructure develops quickly; it has a large chemical difference between phases, with an overall poor chemical durability, and its phases tend toward a higher volume fraction of the lower viscosity phase. Numerous studies have been conducted on its relaxation properties and phase-separation characteristics $[7,10,11,12]$.

In contrast, the second glass (Type II) undergoes a phase separation which is not easily noticeable, and has apparently little effect on the macroscopic properties. It is commonly used for chemical glassware with a composition consisting of $\mathrm{SiO}_{2}, \mathrm{~B}_{2} \mathrm{O}_{3}, \mathrm{Na}_{2} \mathrm{O}$ and $\mathrm{Al}_{2} \mathrm{O}_{3}$ in the proportions: $81: 12.6: 3.9: 2.4$ by weight, as determined by chemical analysis. Its phase-transition temperature is $10 \mathrm{w}\left(649^{\circ} \mathrm{C}\right.$ ) (this measurement is described in Section 3.2.3) and occurs at a high viscosity ( $10^{11}$ poises) (see fig. 1). The microstructure is expected to be small with the phases having little chemical difference.

The viscosity change in both these glasses during phase separation will be investigated and will be related to the growing microstructure by a model developed earlier [7] but modified here. Microstructure measurements on the Type I glass have been reported [13], and we will present results from measurements conducted on Type II samples.

\section{Experimental Section}

\subsection{Microstructure Measurement}

\subsubsection{General}

The samples were in the form of rods 0.1 to $0.2 \mathrm{~cm}$ in diameter (which we will denote as fibers) for the Type I and Type II glasses and rods 0.7 to $1.0 \mathrm{~cm}$ in diameter for the Type II glass only. They were heat treated at elevated temperatures, then quenched to room temperature. The fibers and rods were fractured perpendicularly to the axial direction, and the freshly formed faces were prepared for examination by electron microscopy. Only structure near the center of the fracture faces was measured in order to avoid surface effects. When fibers were' used, they were often also fractured along the axial direction to check for development of any anisotropy in the structure. 
There are generally two significant problems encountered in the examination of phase separated glasses by electron microscopy, and these are particularly pronounced for samples of the Type II glass. First, the two phases have similar compositions and second, the structures have very small domain sizes.

Transmission electron microscopy is suitable for high magnification, and high resolution analysis. However, the minimal differences in electron absorption and lack of contrast due to small composition differences between the phases greatly reduce the utility of the method for this study. Difficulty in thinning the glass without introducing sizeable damage [14], specimen heating and confusion of the true morphology by projection effects [15] further deter from using this method of examination.

The use of shadowed replicas in electron microscopy requires the development of a 3-dimensional surface which depends critically upon the feasibility of differentially etching the phases. Small composition differences as found in the Type II samples make this approach difficult, but with proper etching techniques, the problem can be overcome. Here, care must be taken to dissolve the more soluble phase sufficiently to identify the phase boundaries when Pt is evaporated at a selected angle to the surface (shadowing), without dissolving the less soluble phase and changing its size. Selective solutions are difficult to find, so that it is necessary to use solutions which dissolve both phases and to develop a suitable 3-dimensional structure by the proper selection of strength and duration of the etch. The problem increases with reducing microstructure size, and as will be seen below, structures smaller than 50 to $60 \AA$ are very difficult to shadow properly. Crystallization of the evaporated Pt reduces the resolution and further complicates the analysis of small structures.

Present-state scanning electron microscopy lacks the resolution necessary to provide more than a cursory look at relatively large structures. Therefore, the electron microscopy of Pt-shadowed carbon replicas of etched surfaces offers the most suitable approach to 
measuring microstructure size and volume fraction, and estimating the degree of interconnectivity of the phases.

2.1.2 Etch and Replication Technique

Samples of the Type I glass generally separated into phases with a marked chemical durability difference. Therefore, proper etching was readily accomplished with very weak acid solutions (0.5\% HF in water) [13]. The commercial glass, Type II, besides having small microstructures, separated into phases with a less pronounced chemical durability difference. This required an extensive study of etching solutions and durations.

The criterion which we used to recognize a suitable etch was a surface with depressions caused by the removal of the more soluble phase separated by flat areas representing the durable phase. Any rounding of these areas indicated that the durable phase had been slightly dissolved and indicated uncertainty in the location of the phase boundaries. This is a very stringent requirement, which could not be met adequately at times. However, all microstructure size measurements reported come from micrographs meeting the above criterion.

We used aqueous solutions with $0.5 \%$ to $10 \% \mathrm{HF}, 0$ to $5 \% \mathrm{HCl}$ and 0 to $26 \% \mathrm{H}_{2} \mathrm{SO}_{4}$. It was found that some $\mathrm{HF}$ was necessary in all our solutions. The $\mathrm{HCl}$ and $\mathrm{H}_{2} \mathrm{SO}_{4}$ additions were effective in reducing the etching times without an increase in HF concentrations. This was found desirable, as long etch treatments inevitably resulted in a decrease in the phase boundary definition. In general, the solutions selected changed from a $4.5 \% \mathrm{HF}+26 \% \mathrm{H}_{2} \mathrm{SO}_{4}$ aqueous solution for samples with short heat-treatments ( 4 to 8 hours) to a $1 \% \mathrm{HF}+5 \% \mathrm{HCl}$ aqueous solution for the long heat treatments. (On the basis of normality, a sulfuric acid solution is approximately 3 times stronger than a hydrochloric solution with the same acid volume.) Stronger solutions were required for samples heat-treated at higher temperatures. This follows an expected trend since the chemical difference between phases is less for higher temperatures, and therefore the soluble phase is more durable than at lower temperatures. A comparison of the results of using 
different solutions, where the etch is progressively strengthened on a sample heat-treated at $585^{\circ} \mathrm{C}$ for 96 hours is shown in figure 2 .
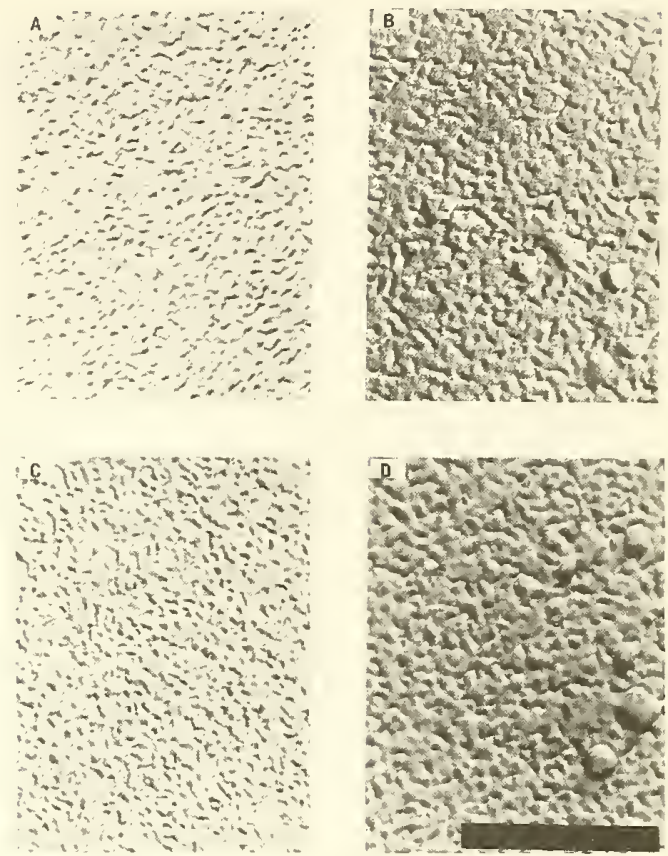

Fig. 2. Micrographs illustrating the variation of the etching solution on a sample treated at $585^{\circ} \mathrm{C}$ for 96 hours. From left to right:

(a) $1 \% \mathrm{HF}+5 \% \mathrm{HCl}$

(b) $1 \% \mathrm{HF}+5 \% \mathrm{H}_{2} \mathrm{SO}$

(c) $1 \% \mathrm{HF}+26 \% \mathrm{H}_{2} \mathrm{SO}^{4}$

(d) $4.5 \% \mathrm{HF}+26 \% \mathrm{H}_{2}^{2} \mathrm{SO}_{4}^{4}$

The bar measures $1 / 2 \mu \mathrm{m}$.

After the acid treatment, we found it necessary to wash the sample in alcohol in order to eliminate the hexagonal $\mathrm{SiF}_{4}$ crystals which resulted from the etch. Once the freshly fractured faces were etched 
and washed, the samples were transferred to a vacuum system (fig. 3)

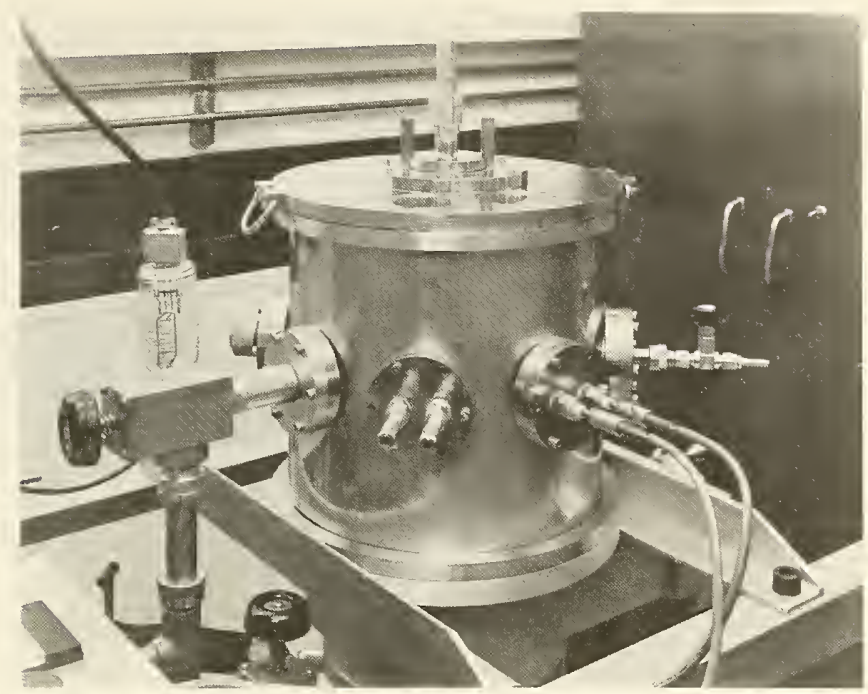

Fig. 3. Bell Jar used for evaporation. The carbon evaporator is at the left; the Pt evaporator is at the right. On top the substrate holder in the middle, and the $\mathrm{N}_{2}$ fill and exhaust lines can be seen.

where the replica was evaporated. The films were evaporated with a background pressure of $2 \times 10^{-6}$ torr or less. The Pt was evaporated first, generally at an angle of $45^{\circ} \mathrm{C}$ to the specimen surface-normal. Smaller angles were used for deep structures and larger ones for shallow structures. The evaporation guns for the Pt and carbon operate by resistance heating of two contacting carbon points (see fig. 4). The lower carbon rod is blunt and held in a fixed position while the pointed upper one is attached to a moveable weighted arm. Contact is maintained during evaporation by gravity only. For the evaporation of Pt, 3 mediums were tried: Pt-carbon pellets, Pt discs, and Pt wire 
held between two carbon points as in figure 4; the latter being our

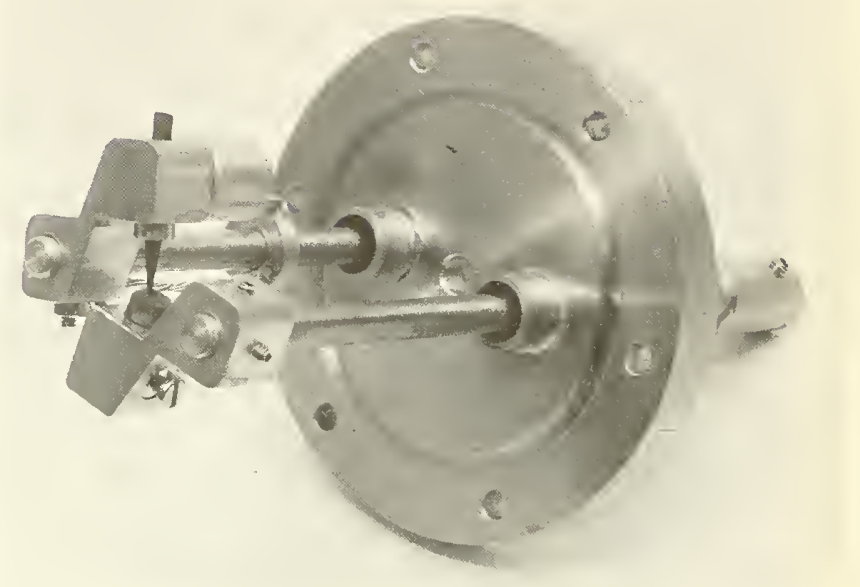

Fig. 4. Carbon resistance heating evaporator. The pointed carbon rod is kept against the lower blunt rod by gravity only. When Pt wire is used, it is wound around the point of the upper rod.

choice. The pellets gave a coarser replica, and the discs required a high current to melt, causing carbon to be evaporated as_well. This produced either a good Pt film but a coarse replica, or a fine grain replica with insufficient Pt. Fine Pt wire (.13mm dia., $3 \mathrm{~cm}$ long) wound tightly around the upper carbon rod gave the best results. In the evaporation of $\mathrm{Pt}$ and carbon, we always tried to make the films as thin as possible $(<100 \AA)$.

The guns were designed to fit inside a shield with a small restricting aperture aligned with the etched glass substrate, in order to insure a direct, controlled jet of carbon or Pt vapor at the sample. The sample was in turn surrounded by a liquid nitrogen shield with two apertures. This reduced contamination of the substrate and the films from the surrounding surfaces and reinforced the control over the vapor 
from the carbon and Pt sources. The stringent restriction on the beam of particles reaching the substrate enabled us to obtain clear and high resolution micrographs showing well-defined phase boundaries. This is reflected in our ability to replicate and measure microstructure as small as $60 \AA$ in size when $100 \AA$ was the previous limit. There are provisions in the system for cooling the specimen, however, we found that this had no substantial effect on the replicas produced.

The replicas were removed from the glass samples by stripping in a 5\% HF aqueous solution. The floating replica was picked up with a copper grid disc and washed in distilled water. The replicas were examined in an electron microscope, generally at a magnification of 22,000 to 65,000 times. Resulting micrographs are shown in figures 5-8 for the $620,600,585$ and $565^{\circ} \mathrm{C}$ isotherms.

\subsubsection{Size Measurement}

The size of the microstructure was obtained in two steps. First, a straight line was drawn through a photograph of the replica and the cumulative length of the portions associated with each phase was measured. This was done in several random directions and determined the volume fraction of each phase. Then from the total number of intersections of each line with a phase boundary, the average distance between phase changes was calculated. In general, we made 10 measurements of lines with 100 to 120 intersections. This yielded uncertainties below $10 \%$ and usually around $5 \%$ of the numbers obtained, except when the sizes were smaller than $150 \AA$. In the latter case, our uncertainty was around $20-25 \AA$.

\subsection{Viscosity Measurement}

The shear viscosity was measured by the fiber elongation technique described in detall elsewhere [16] (see fig. 9), because it offers two essential features. The method lends itself well to a continuous measurement of the viscosity as a function of time at a fixed temperature, and allows these measurements to be started immediately after insertion of the fiber into the furnace. Analysis of the data obtained demonstrates that the latter feature is necessary for a good 

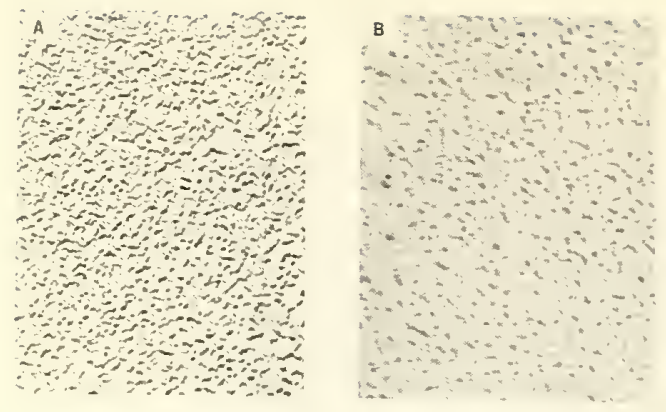

Fig. 5. Micrographs showing the $620^{\circ} \mathrm{C}$ isotherm for heat treatments lasting:
(a) 8 hours
(b) 48 hours
(c) 192 hours
(d) 768 hours
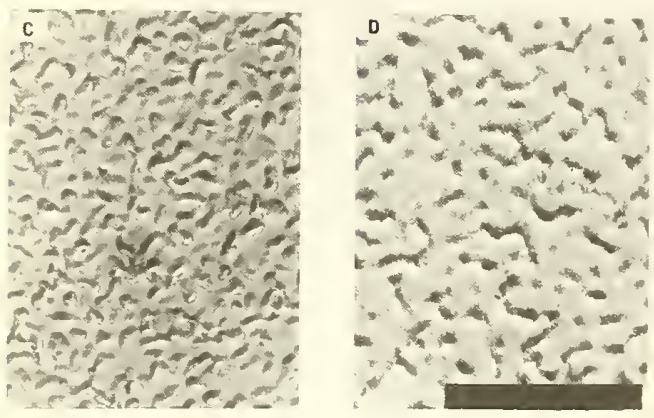

The bar is $1 / 2 \mu \mathrm{m}$.

Fig. 6. Micrographs showing the $600^{\circ} \mathrm{C}$ isotherm
(a) 24 hours
(b) 48 hours
(c) 96 hours
(d) 192 hours
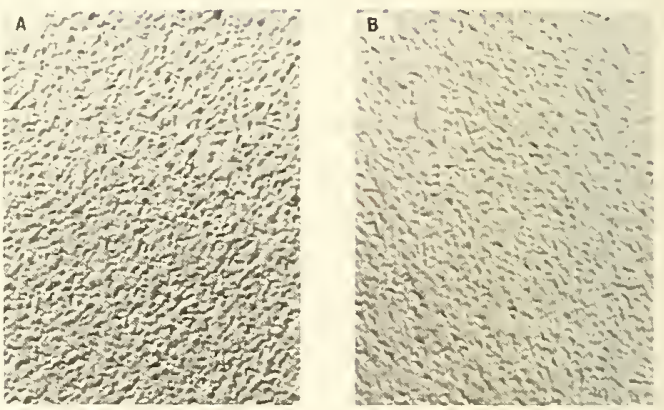

The bar is $1 / 2 \mu \mathrm{m}$.
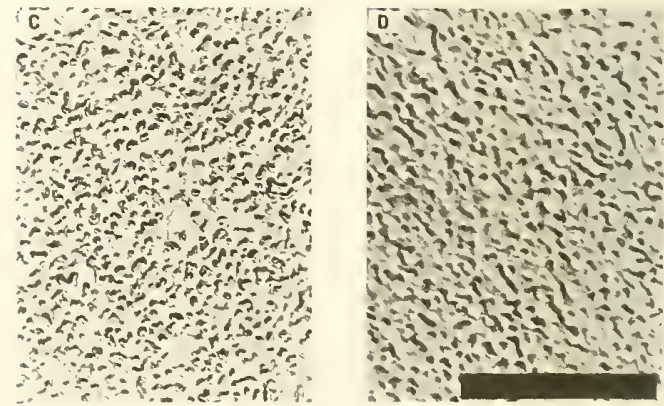

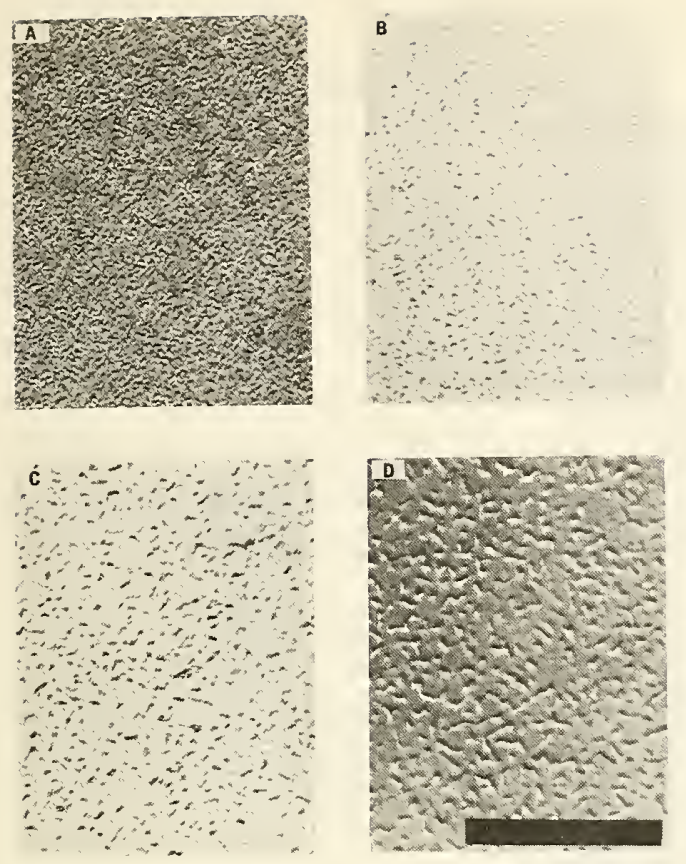

Fig. 7. Micrographs showing the $585^{\circ} \mathrm{C}$ isotherm
(a) 24 hours
(b) 48 hours
(c) 96 hours
(d) 192 hours

The bar is $1 / 2 \mu \mathrm{m}$.
Fig. 8. Micrographs showing the $565^{\circ} \mathrm{C}$ isotherm
(a) 24 hours
(b) 48 hours
(c) 96 hours
(d) 192 hours

The bar is $1 / 2 \mu \mathrm{m}$.
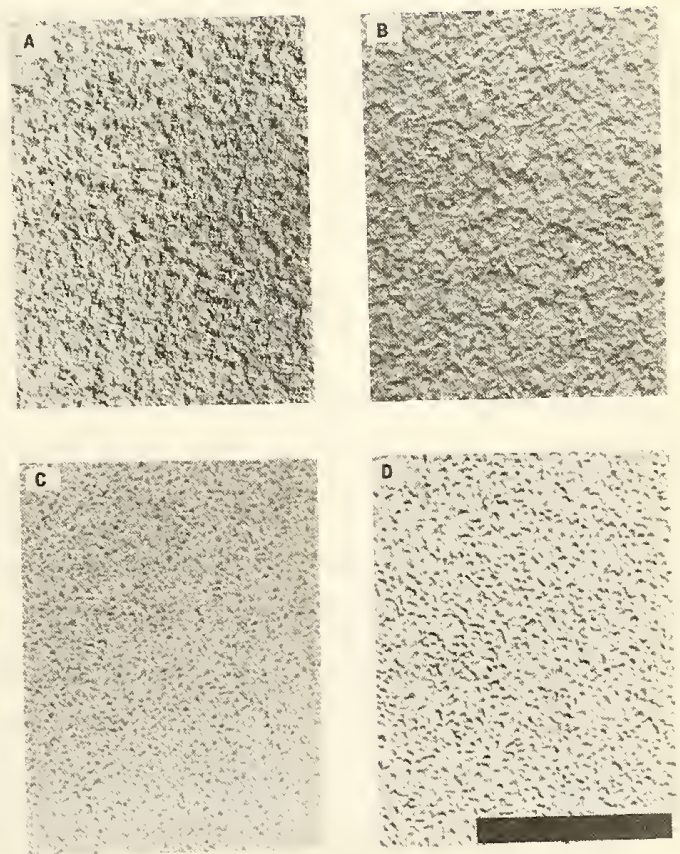


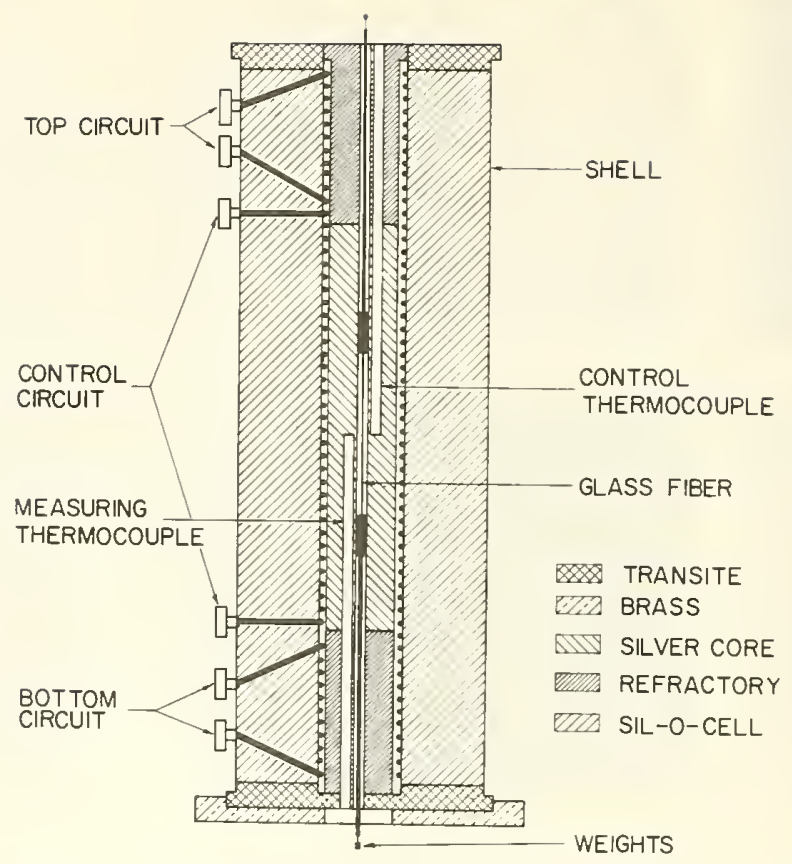

Fig. 9. Fiber elongation apparatus reprinted from reference 16 .

interpretation of the results [11].

The behavior of the isothermal viscosity as a function of heattreatment time was measured by continuous recording of the elongation of the fiber. Special care was taken to begin the measurements within the first minute after insertion of the fiber into the hot furnace. It is estimated that the fibers reached the heat-treatment temperature in less than 2 minutes. The measurements were then continued for times lasting up to 150,000 minutes. Some fibers were loaded immediately, and others were heat-treated for different time periods before the load was applied in order to determine the delayed elastic effects. Several measurements were conducted at the same temperature, but with different loads in order to detect stress-dependent behavior. 


\subsection{Analysis of Microstructure Growth}

In both glasses, the structure appeared to grow in size during the isothermal heat treatments. The volume fractions of each phase remained constant throughout the measurements. The volume fractions of durable to soluble phase are 50:50 and 55:45 for Type I and Type II glasses, respectively. The change in etching solution necessary for the analysis of the structure in the Type II samples indicated that the chemical composition of the phases may have changed during the heat treatments as a function of both temperature and treatment duration. This question is deferred to another report [17] where the chemical durability of the samples is measured as a function of heat-treatment time and temperature. Further analysis of the micrographs indicated that the interconnectivity remained high throughout the microstructure growth. These results, when taken together, suggest that we are observing primarily the rearrangement stage of the phase separation process.

It is now necessary to ascribe a microstructure size to each micrograph and analyze the change of this quantity with heat-treatment time and temperature. An easily measured quantity, as shown before, is the distance between consecutive phase changes. However, in order to remain consistent with out previous work on the subject $[7,13]$, let us determine a correlation length to characterize the phases. This is done through a correlation function, $G(r)_{2}$ which represents the increased probability due to phase separation of going a distance $r$ from any point and remaining within the same phase. The distance between phase changes, $\bar{r}$, is therefore defined as:

$$
\bar{r}=\int r G(r)\left[4 \pi r^{2} d r\right] / \int G(r)\left[4 \pi r^{2} d r\right]
$$

Using a probability function previously shown to describe these systems wel1 [Ref. 7]:

$$
G(r)=G_{0} \exp \left[-r^{2} / 2 \Lambda^{2}\right]
$$

where $G_{0}$ is a constant and $\Lambda$ is the correlation length, we obtain the 
following relationship:

$$
\Lambda=0.63 \bar{r} \text {. }
$$

The isothermal time dependence of the correlation length, $\Lambda$, may be readily calculated from the measured dependence of $\bar{r}$ on heattreatment time and temperature. The data for the Type I glass were reported in Ref. 13. Those for the Type II glass are shown in figure 10.

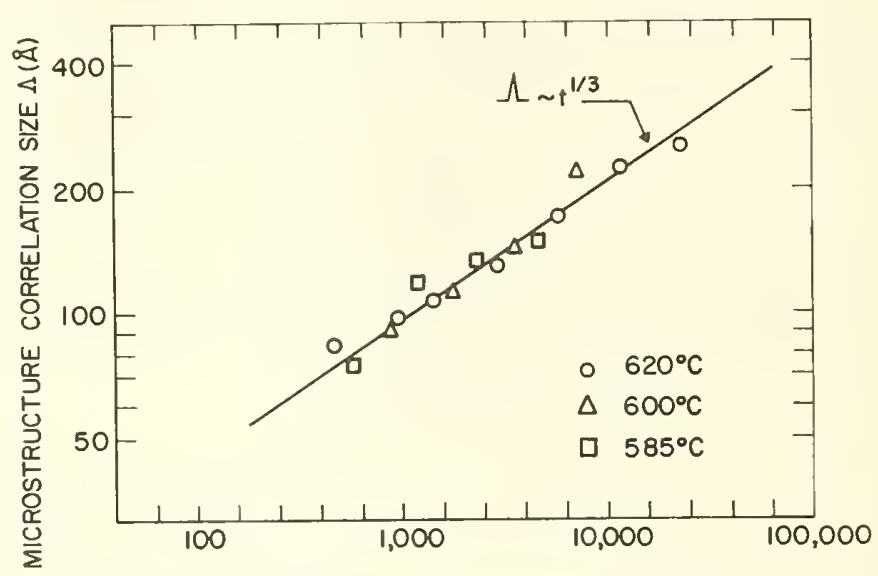

TIME AT $620^{\circ} \mathrm{C}$ CORRESPONDING TO THE

$$
\text { REDUCTION: } t^{*}=t e^{E_{2}} /{ }^{R T} /\left(1-T / T_{c}\right)
$$

$(\min )$

Fig. 10. Plot of correlation length, $\Lambda$, against reduced time:

$$
t *=t e^{E_{2} / R T} /(1-T / T c)
$$

The line follows $1 / 3$ power of time.

Both glasses follow a $1 / 3$ power dependence of structure size on time, generally expressed as [18]:

$$
\Lambda^{3}(T, t)-\Lambda_{0}^{3}(T)=D\left(t-t_{0}\right)
$$

with the time and size at which this 1/3 power-1aw behavior begins $\left(\Lambda_{0}\right.$ and $\left.t_{0}\right)$ sufficiently smaller than the values reported that they may 
be ignored. Near the transition temperature, the diffusion coefficient, $D$, can be expressed in terms of a mobility term and the chemical potential with the following result:

$$
\Lambda^{3}(T, t)=D_{0}\left(1-T / T_{c}\right) t e^{-E_{2} / R T}
$$

where $D_{0}$ is a constant; $t$ is the time; $T$ is the temperature; $T_{c}$ is the transition temperature, and $E_{2}$ is the activation energy controlling the diffusion process by which the phase rearrangement is occurring. The parameters of the fit of the data to this equation are as follows:

Type I Glass

$$
\begin{aligned}
& \mathrm{D}_{\mathrm{o}}=1.19 \times 10^{30} \AA^{3} / \mathrm{min} \\
& \mathrm{E}_{2}=97 \mathrm{kcal} / \mathrm{mol}\left(4.06 \times 10^{5} \mathrm{~J} / \mathrm{mol}\right)
\end{aligned}
$$

Type II Glass

$$
\begin{aligned}
& D_{0}=8.6 \times 10^{22} \AA^{3} / \mathrm{min} \\
& \mathrm{E}_{2}=70 \mathrm{kcal} / \mathrm{mol}\left(2.93 \times 10^{5} \mathrm{~J} / \mathrm{mol}\right)
\end{aligned}
$$

Since bulk diffusion through the fluid phase is likely to be the rate controlling step, as indicated by the $1 / 3$ power relationship of Eq. 5 between time and size, then we may assume that it is characterized by an activation energy whose value is $\mathrm{E}_{2}$.

\subsection{Analysis of Viscosity Change}

3.2.1 General

The isothermal viscosity measured at this laboratory for the two glasses under consideration is shown in figures 11 and 12 . It is interesting to note in passing that despite the large viscosity differences between the two glasses above and at the transition temperature (fig. 1), the range of temperatures for which the viscosity is suitably measured by the fiber elongation method is the same, $540-660^{\circ} \mathrm{C}$.

Figures 11 and 12 show that the isothermal viscosity increases by as much as five orders of magnitude over the heat-treatment times studied. Before correlating this increase to microstructure development, we must identify the effect of the elastic response from application of 
Fig. 11. Composite illustration of the isothermal viscosity of samples of Type I glass from $620^{\circ} \mathrm{C}$ to $540^{\circ} \mathrm{C}$. The solid lines represent the fit of the data by the relaxation model (Eqs, 12 and 13). The lower right plot shows how, by the complexity of the viscosity effect, there are heat-treatment times between 10 and 100 minutes when the viscosity at $560^{\circ} \mathrm{C}$ is lower than at $600^{\circ} \mathrm{C}$. 

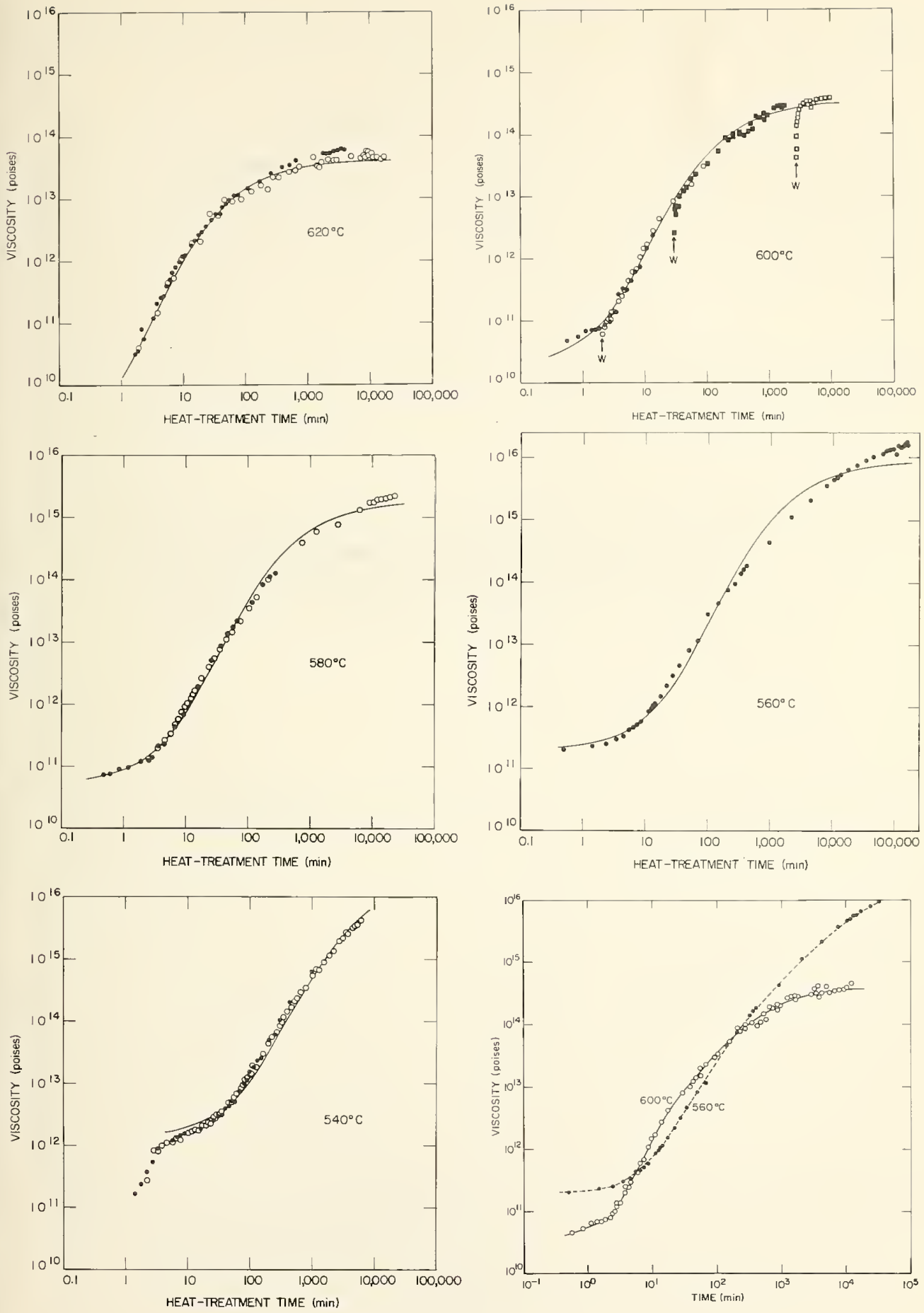

17 
Fig. 12. Composite illustration of the isothermal viscosity of samples of the Type II glass from $545^{\circ} \mathrm{C}$ to $660^{\circ} \mathrm{C}$. The solid lines represent the fit of the data by the relaxation model (Eqs. 12 and 13). 

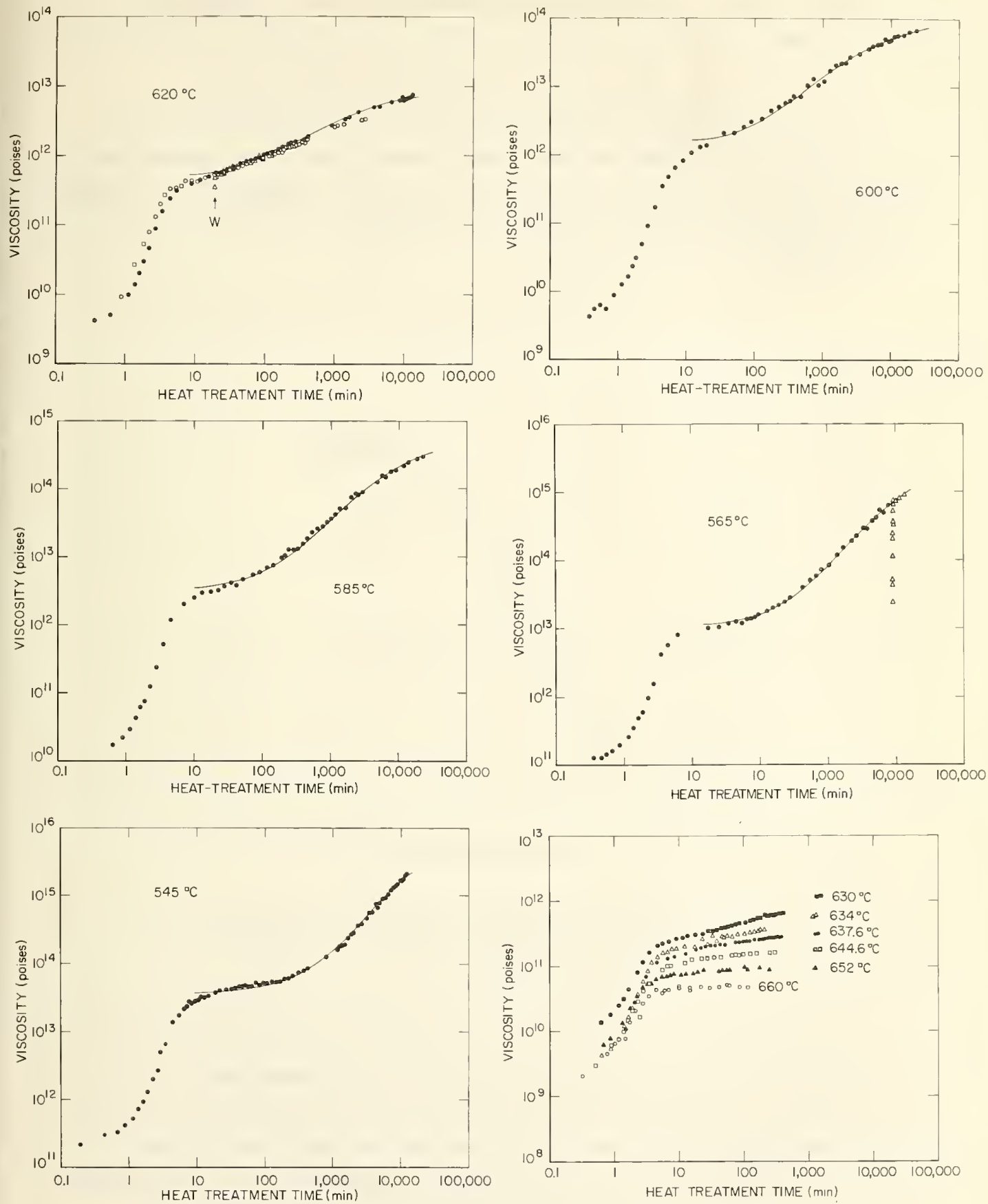
the load at the beginning of the viscosity measurement (delayed elastic effect).

\subsubsection{Effects Associated with Application of the Load}

For the Type I glass samples, several sets of measurements were made at $600^{\circ} \mathrm{C}$. The unloaded fibers were inserted into the furnace and then were loaded after different lengths of heat treatment to detect and identify the delayed elastic effects (see fig. 13).

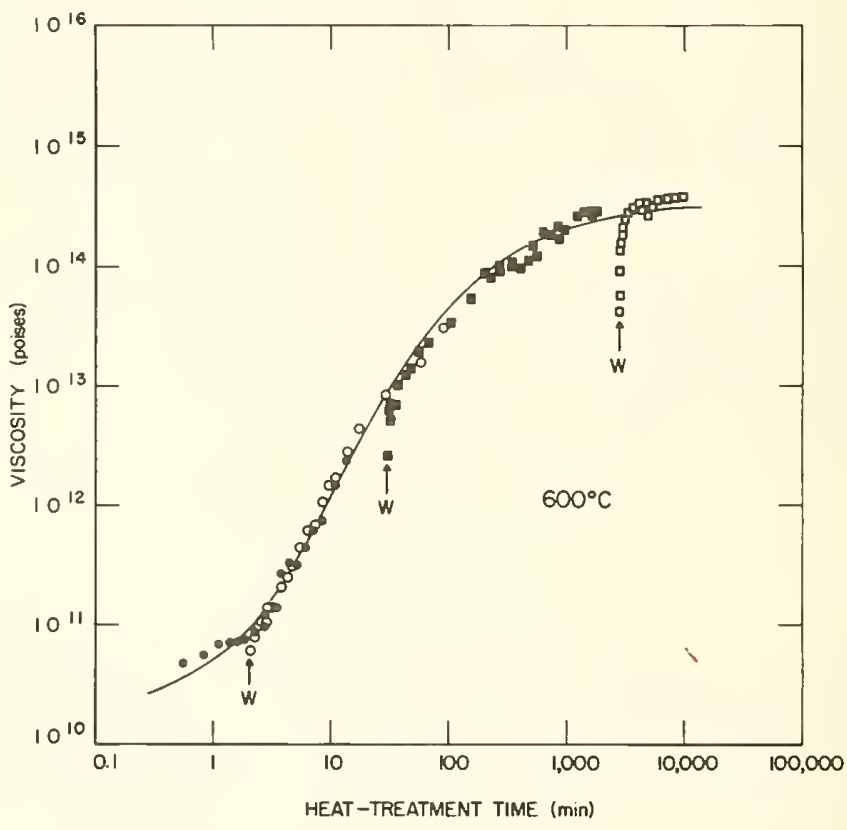

Fig. 13. Test of delayed elastic effects in samples of Type I at $600^{\circ} \mathrm{C}$. W indicates load application.

If the viscosity change observed is a delayed elastic effect and not due to phase separation, then it will take the same time after loading for the viscosity to reach a given value, whether the load was applied immediately after the fiber was inserted into the furnace, or after a long elapsed time at the measuring temperature. In other words, the duration of the heat treatment prior to loading should have no 
effect on the measured time-dependent viscosity after loading. This test is shown in table 1 . The first column of table 1 lists the

Table 1. Test for the Increase in Viscosity

\begin{tabular}{cccc}
\hline $\begin{array}{c}\text { Equilibrium viscosity } \\
\text { when load was applied }\end{array}$ & $\begin{array}{l}\text { Time at which } \\
\text { load was } \\
\text { applied } \\
\text { Poises }\end{array}$ & $\begin{array}{l}\text { Measured time } \\
\text { for relaxation } \\
\text { of delayed } \\
\text { elastic effect } \\
\text { Minutes }\end{array}$ & $\begin{array}{c}\text { Calculated time } \\
\text { for relaxation } \\
\text { elastic effect } \\
\text { Minutes }\end{array}$ \\
$10^{11}$ & 2 & 0.2 & 0.1 \\
$10^{13}$ & 30 & 10 & 11.5 \\
$1.3 \times 10^{14}$ & 400 & 150 & 150 \\
$2.6 \times 10^{14}$ & 1580 & 240 & 300 \\
$3.6 \times 10^{14}$ & 6320 & 600 & 450 \\
\hline
\end{tabular}

viscosity of samples loaded immediately after insertion into the furnace but corresponding to an elapsed time listed in column 2. Other fibers were heat-treated for the same times before loading (delayed-1oaded). The third column then lists the time taken by the viscosity of the delayed-loaded specimens to reach the viscosity value listed in column 1. If the viscosity change observed on fibers loaded immediately after insertion into the furnace is a delayed elastic effect, then columns 2 and 3 should list equal times, i.e., the viscosity curves should be identical regardless of the elapsed heat-treatment time prior to loading. It is evident from the table that column 2 lists times much larger than column 3, particularly for the higher viscosities. Therefore, it can be concluded that the viscosity change observed on the fibers loaded immediately upon insertion into the furnace is not a delayed elastic effect but rather a true viscosity change. In these cases, due to the initial low viscosity, the expected delayed elastic effect is hidden by the 2-minute warm-up period, as shown below. 
A delayed elastic effect on the viscosity is, however, visible at $540^{\circ} \mathrm{C}$ for times less than 3 minutes, due to the high starting viscosity.

The delayed elastic effects can be further investigated by studying the fibers which were loaded after different heat-treatment durations. The times taken for their viscosities to reach the instantaneouslyloaded curve are listed in column 3 and represent the relaxation of the applied stresses. At any time during the heat treatment, these values are related to the viscosity by the expression:

$$
\tau_{D E}=C_{0} \bar{\tau}=C_{0} n / G_{\infty}
$$

$C_{0}$ relates the observed elastic effect relaxation time to the average relaxation time $\bar{\tau}$, and we shall assume that it remains unchanged with phase separation. The shear modulus, $G_{\infty}$, of an immiscible system undergoes little change due to composition fluctuations, and therefore, will also be assumed to be independent of phase separation. The observed time for the relaxation of the delayed elastic effects is thus directly proportional to the viscosity at the application of the load. By calculating the proportionality constant for one of the delayed loadings $\left(\tau_{\mathrm{DE}}=150 \mathrm{~min}\right.$ for $n=1.3 \times 10^{14}$ poises $)$, we can test the relationship for the other loadings. The times thus calculated from Eq. (6) are listed in column 4 of table 1 . The good agreement between columns 3 and 4 indicates that the times listed in column 3 indeed represent the relaxation of the delayed elastic effects by a shear flow process characterized by the viscosity listed in column 1 .

Fibers loaded at a viscosity of $10^{11}$ poises exhibit delayed elastic effects for only 0.1 minutes, therefore, the viscosity curves of fibers loaded immediately after insertion into the furnace (fig. 11) represent real changes in the viscosity as a function of time after heat-treatments of 2 minutes (warm-up period).

Measurements were also made with loads varying up to $2,5001 \mathrm{~b} / \mathrm{in}^{2}\left(1.72 \times 10^{7} \mathrm{~N} / \mathrm{m}^{2}\right)$. No stress-dependent behavior was observed, indicating that Newtonian viscous flow is occurring during the measurements. 
The same test was conducted on samples of the Type II glass at $565^{\circ} \mathrm{C}$ and $620^{\circ} \mathrm{C}$ (fig. 12). Here the analysis is more complicated since the curves reveal two separate periods of viscosity increase. Examining the results of loading the fibers after different treatment durations, indicates that neither apparent viscosity increase is caused by the effect of applying the load. As in the first glass, varying the applied loads showed the viscosity to be stress independent, up to stress levels of $2,500 \mathrm{psi}\left(1.72 \times 10^{7} \mathrm{~N} / \mathrm{m}^{2}\right)$.

\subsubsection{Phase-Transition Temperature Measurement}

The phase-transition temperature of the Type I glass was measured by the opalescence-clearing method which is described in detail in ref. 8. However, this convenient technique could not be used on samples of Type II because opalescence was very difficult to achieve. (We have one sample of Type II which scatters light with the characteristic blue color, and it was heat-treated for approximately two months at $590^{\circ} \mathrm{C}$.) Therefore, we resorted to the viscosity measurements to determine the transition temperature.

Measurements of the isothermal viscosity at 652 and $660^{\circ} \mathrm{C}$ exhibited no time dependence after the first three minutes (see fig. 12, lower right). Since this period is not long enough to reach equilibrium in a phase-separating system due to the high viscosity of the glass, it was concluded that these temperatures were above the phase-transition temperature. (See the next section for a discussion of the early viscosity changes.) Below $652^{\circ} \mathrm{C}$, the isothermal viscosity increases with time in an approximately linear fashion on a $\log -\log$ plot. The slope of this dependence was found to vary linearly with temperature and goes to zero at $649^{\circ} \mathrm{C}$ (see fig. 14). Since this slope is a measure of the phase separation effect on the viscosity, the intercept at $649^{\circ} \mathrm{C}$ is the phase transition temperature. 


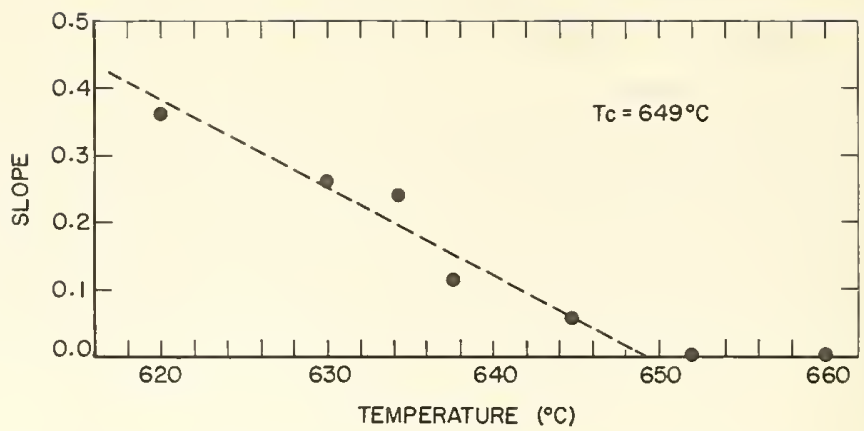

Fig. 14. Measurement of temperature for which the time dependence of the viscosity ceases.

\subsubsection{Effects Associated with the Microstructure Growth}

The analysis of microstructure development in the glasses investigated indicates that the increase in microstructure size is the primary change occurring during the viscosity increase. The volume fractions remain constant, and the differences in phase composition between samples of Type II treated at different temperatures has been discussed. Following Eq. 5, we may plot the isothermal viscosity as a function of microstructure size in figures 15 and 16 . The curves demonstrate the same behavior. In the Type II glass samples, however, the early increase in viscosity also occurs at temperatures above the phase transition temperature: 652 and $660^{\circ} \mathrm{C}$, where only supercritical composition fluctuations may exist.

The effect is not simply due to heating of the fiber to the treatment temperature because it lasts longer than the 2-minute heating time at the lower temperatures, and because simple heating would cause a decrease in viscosity. Our microstructure size measurements at later times indicate that significant subcritical microstructure growth does not occur during these short treatment times and, therefore, cannot account for the effect. 


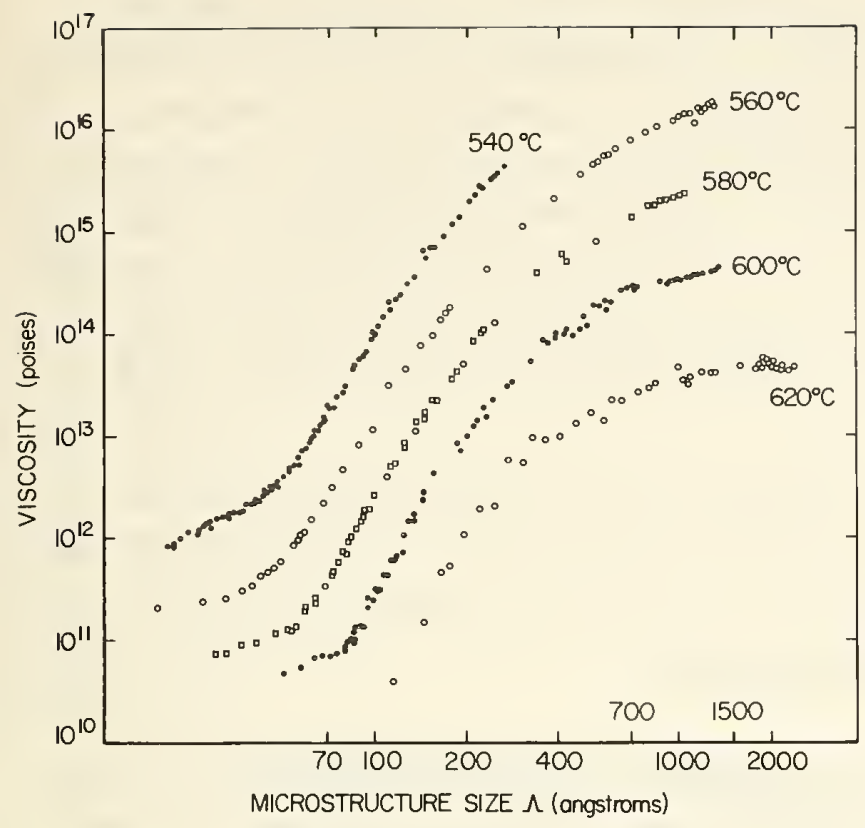

Fig. 15 .

Viscosity of Type I samples plotted as a function of microstructure size, $\Lambda$.

Fig. 16.

Viscosity of Type II samples plotted as a function of microstructure size, $\Lambda$.

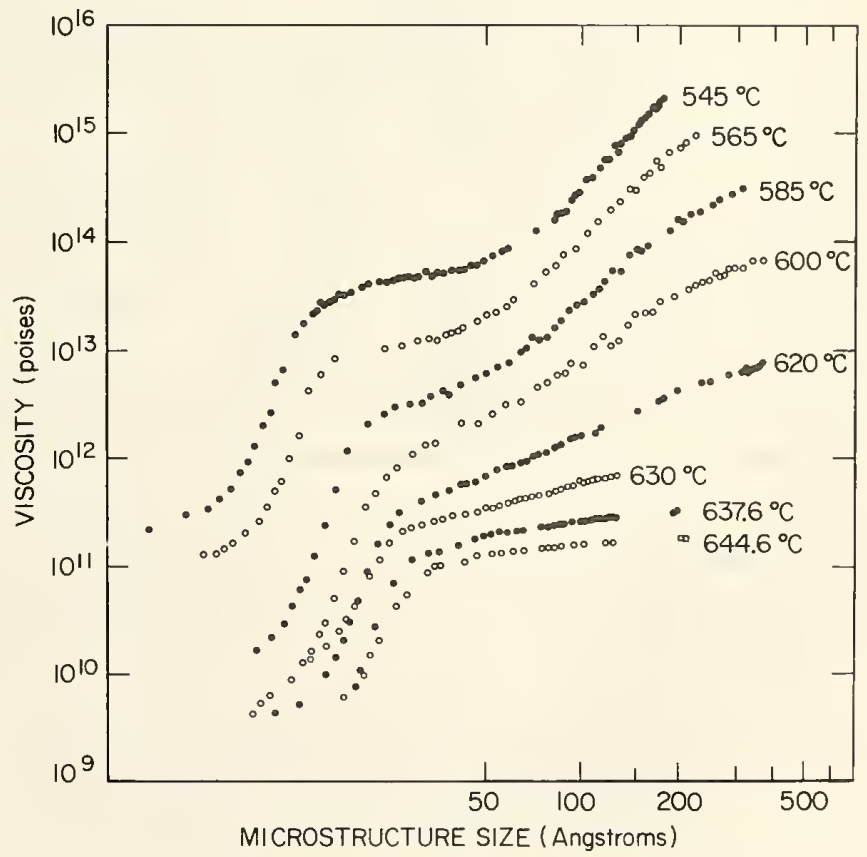


There are two possible processes which can result in this early increase in viscosity. This is an expulsion of water from the glass in heating, or the growth of supercritical composition fluctuations. Vacuum infrared absorption measurements and a microscopic examination of fibers heat-treated for very short times are needed for a further analysis of the effect. These are both difficult tests and it appears that the effect is not related to subcritical microstructure growth, therefore, we will defer further discussion of the effect to another report.

Herein we shall analyze the entire viscosity increase in the Type I glass and the later increase in the Type II glass in terms of the associated microstructure growth as shown in figures 15 and 16 .

\subsection{Formulation of Viscosity Change}

\subsubsection{Mode1}

A model describing the effect of point-to-point variations in the local molecular environment of inorganic glasses on the viscous flow processes has been proposed [7].

This model is an outgrowth of viscous relaxation measurements conducted in a series of soda-borosilicate glasses above their phaseseparation temperatures $[7,10]$. (One of the glasses in the series is identical to the material investigated herein denoted as Type I.) Above the phase-separation temperature, composition fluctuations occur in the melt, and have well characterized temperature-dependent wavelengths and lifetimes. These fluctuations, in effect, produce distributions of local molecular environments which vary with temperature. The effect of changes in these local environments on viscous flow was investigated by shear ultrasonic spectroscopy. It was found that viscous flow was greatly affected by differences in local molecular environments around flow species in the melt. The environmental relaxation model developed in that investigation describes quantitatively the behavior of the distribution of shear relaxation times as a function of temperature for changing distributions of microstructure sizes. 
The model is based upon the concept that the shear structural relaxation processes which control the viscosity are highly dependent upon the size and type of microstructure present in the melt. If one has a system whose interconnected microstructure may be represented by two phases of widely different viscosities there are three types of viscosity behavior which will ensue, depending upon microstructure size only. The latter which we will denote by $\Lambda$ is considered relative to a size, $r_{0}$, which represents the range of influence for viscous flow of a molecule. A sphere of radius, $r_{0}$, is defined such that the composition of a region contained within it has a direct effect upon the shear structural relaxation properties of the molecule in the center, while the region outside $r_{0}$ has no effect. There are, therefore, three viscosity regions which can be characterized by the ratio $\Lambda / r_{0}$ (see fig. 17).

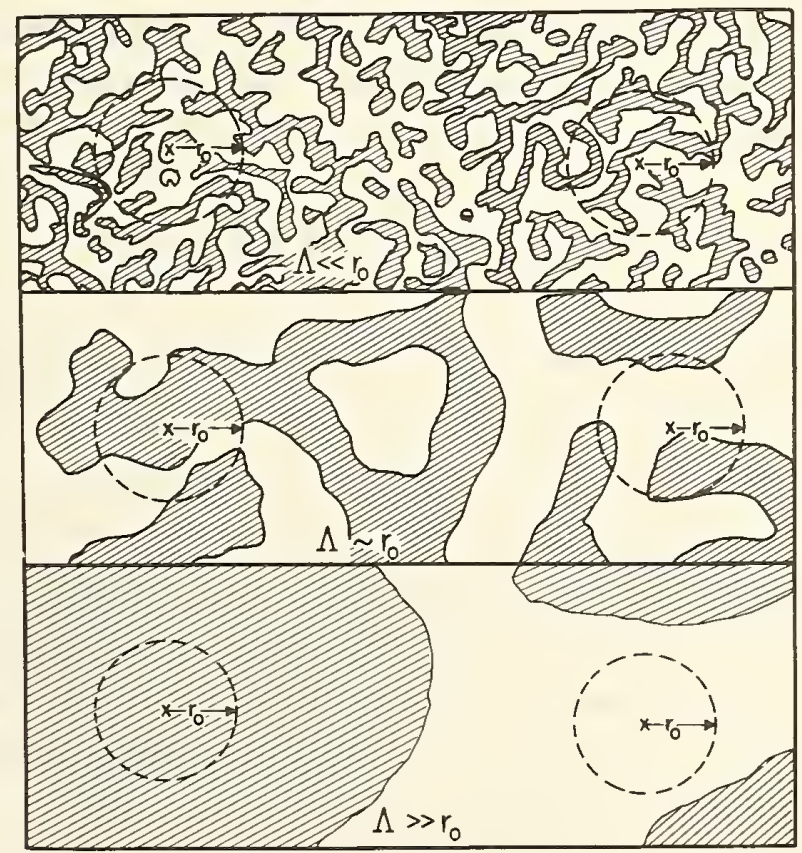

Fig. 17. Graphical demonstration of the effect of relative sizes, $\Lambda / \mathrm{r}$, on the viscous flow properties of molecules located in each phase. 
In the case of very small microstructure, $\Lambda<<I_{0}$, space averaging within $r_{0}$ leads to similar compositional make-up around the various molecules. Their relaxation times or activation energies are equivalent. Therefore, distributions are narrow and normal viscosity behavior is expected. As the microstructure grows, $\Lambda_{\mathrm{r}_{\mathrm{o}}}$, the neighborhoods differ and lead to non-equivalent relaxation times or activation energies. This produces a broadening distribution of relaxation times and leads to an anomalous increase in viscosity. The broadening in the distribution and increase in viscosity are accentuated as $\Lambda$ grows. However, for very large microstructure sizes, $\Lambda \gg r_{0}$, most neighborhoods are well embedded within the fluctuations and further changes in $\Lambda$ have relatively little effect on their relaxation properties. The distributions are broad, but are no longer dependent on $\Lambda$. The anomalous viscosity increase saturates.

The formulation of the model [7] leads to an expression for the width of the distribution of activation energies in terms of the ratio of microstructure size to range of influence, $\Lambda / r_{0}$.

$$
\left\langle(\delta E)^{2}>=\operatorname{RT} \Delta \mathrm{E}\left(\Lambda / r_{0}\right)=\operatorname{RT} \Delta \mathrm{E}\left[\frac{1}{1+\left(r_{0} / \Lambda\right)} 2\right]^{3 / 2}\right.
$$

where $\Delta \mathrm{E}$ is a constant representing the difference in activation energies between the totally mixed state $\mathrm{E}_{0}$, and either phase after total separation. Implicit in this expression is the formulation of the activation energy spectrum in terms of a Gaussian distribution (i.e., the definition of $\left.\left\langle(\delta E)^{2}\right\rangle\right)$. In this case, $E_{0}+1 / 2 \frac{\left\langle(\delta E)^{2}\right\rangle}{R T} i^{2}$ the activation energy of the viscous phase, and $E_{0}-1 / 2 \frac{\left.<\frac{{ }^{R T}}{R T}\right)^{2}>}{R T}$ is the activation energy ascribed to the fluid phase. The function $f\left(\Lambda / r_{0}\right)$ represents the gradual broadening of the distribution resulting from an increase in structure size, $\Lambda$.

A Gaussian distribution describes well the effect of supercritical fluctuations, however, below $\mathrm{T}_{c}$, the changes in composition are larger and thus, the differences in activation energies between the phases are high and more suitably represented by two well separated values. 
Another modification is necessary because the effect of microstructure on the activation entropy was neglected for simplicity in the analysis of reference 7 . Since this provided a good fit of the data, the activation entropy contribution was left out of the model. As will be seen in the subsequent analysis below, the data from the Type II glass cannot be treated without an activation entropy contribution. Therefore, we will introduce this term into equation ( $7 a$ ) before proceeding.

$$
<(\delta \mathrm{H})^{2}>=\mathrm{RT} \Delta \mathrm{H} \mathrm{f}\left(\Lambda / \mathrm{r}_{\mathrm{o}}\right)=\mathrm{RT} \Delta \mathrm{H}\left[\frac{1}{1+\left(\mathrm{r}_{\mathrm{o}} i \Lambda\right)}\right]^{3 / 2}
$$

where the activation enthalpy is a sum of the activation energy and entropy: $\Delta \mathrm{H}=\Delta \mathrm{E}-\mathrm{T} \Delta \mathrm{S}$.

We consider, below, the case where the volume fractions are not equal, and the distribution is bimodal. The viscosity at any temperature or time is a measure of the average relaxation time, $\bar{\tau}$, of the system:

$$
\eta(T, t)=G_{\infty} \bar{\tau}=G_{\infty} \int_{-\infty}^{\infty} \bar{\tau} g(\ln \tau) d \ln \tau
$$

$\mathrm{g}(\ln \tau)$ is the viscoelastic distribution of relaxation times and $G_{\infty}$ is the solid-like shear modulus. In terms of activation enthalpies the viscosity is written as:

$$
n(T, t)=G_{\infty} A \int_{-\infty}^{\infty} e^{H / R T} g(H, t) d H
$$

$A$ is the pre-exponential from the rate equation. The activation enthalpy distribution $\mathrm{g}(\mathrm{H})$ may now be written as:

$$
g(\mathrm{H}, \mathrm{t})=\mathrm{v}_{1} \delta\left(\mathrm{H}-\mathrm{H}_{1}\right)+\mathrm{v}_{2} \delta\left(\mathrm{H}-\mathrm{H}_{2}\right)
$$

where $\mathrm{v}_{1}$ and $\mathrm{v}_{2}$ are the respective volume fractions, and the viscous phase has $H_{1}=H_{0}+\Delta H_{1} f\left(\Lambda / r_{0}\right)$ and the fluid phase has $H_{2}=H_{0}-\Delta H_{2} f\left(\Lambda / r_{0}\right)$. 
This has the following result on the viscosity:

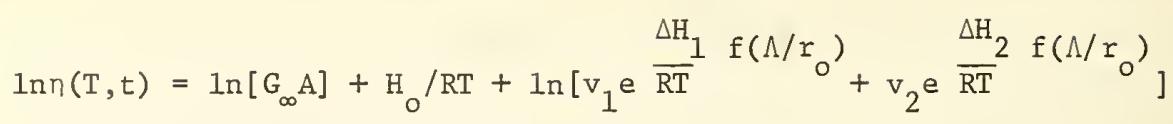

where $\Lambda$ contains the implicit time dependence. Unless $\mathrm{v}_{2} \gg>\mathrm{v}_{1}$, or $\Delta \mathrm{H}_{2}$ is very small ( $<4 \mathrm{kcal} / \mathrm{mol}$ ) the second term in the right-hand bracket is always negligible at the temperatures considered since $f\left(\Lambda / r_{0}\right)$ only varies between 0 and 1 .

The expression for the time-dependent viscosity may then be simplified to:

$$
\operatorname{lnn}(T, t)=\operatorname{lnn}(T, 0)+\frac{\left(\Delta E_{1}-T \Delta S_{1}\right.}{-R T} \quad\left\{\frac{1}{1+\left[r_{0} / \Lambda(t)\right]} 2\right\}^{3 / 2}
$$

where the mixed system has the viscosity:

$$
\ln n(T, 0)=\ln \eta_{0}+E_{0} / R T .
$$

The constant $\mathrm{S}_{\mathrm{O}} / \mathrm{R}$ is incorporated in $1 \mathrm{n} \eta_{\mathrm{O}}$. The temperature dependence is explicitly shown in the equation and only the value of the deviation of the viscous phase activation enthalpy from the mixed system $\left(\Delta \mathrm{H}_{1}=\Delta \mathrm{E}_{1}-\mathrm{T} \Delta \mathrm{S}_{1}\right)$ affects the result. The time dependence and the effect of the activation energy for flow in the fluid phase are introduced through the microstructure size, $\Lambda$, as in Eq. (5).

\subsubsection{Analysis of Results}

The model allows for a fit of the viscosity data and this is shown by the solid line in figures 11 and 12, with the following parameters: 
Type I Glass

$$
\begin{aligned}
& r_{0}=57 \AA \\
& \ln n_{0}=-50.43 \\
& \mathrm{E}_{\mathrm{o}}^{\mathrm{O}}=128 \mathrm{kcal} / \mathrm{mol}\left(5.35 \times 10^{5} \mathrm{~J} / \mathrm{mol}\right) ; \Delta \mathrm{S}_{1}=0 \\
& \mathrm{E}_{2}=97 \mathrm{kcal} / \mathrm{mol}\left(4.06 \times 10^{5} \mathrm{~J} / \mathrm{mol}\right) \\
& \Delta \mathrm{E}_{1}(620)=18.9 \mathrm{kcal} / \mathrm{mol} \quad \Delta \mathrm{E}_{1}(580)=17.8 \quad \Delta \mathrm{E}_{1}(540)=15.6 \\
& \Delta \mathrm{E}_{1}(600)=18.2 \quad \Delta \mathrm{E}_{1}(560)=17.8
\end{aligned}
$$

Type II Glas

$$
\begin{array}{rlrl}
\mathrm{r}_{0} & =58 \AA \\
1 \mathrm{n} n_{0} & =-20.20 \\
\mathrm{E}_{0} & =84 \mathrm{kcal} / \mathrm{mol} & \left(3.51 \times 10^{5} \mathrm{~J} / \mathrm{mol}\right) \\
\mathrm{E}_{2} & =70 \mathrm{kcal} / \mathrm{mol} & \left(2.93 \times 10^{5} \mathrm{~J} / \mathrm{mol}\right) \\
\Delta \mathrm{S}_{1} & =33.6 & & \\
{ }_{1} & & & \\
\Delta \mathrm{E}_{1}(620) & =65.1 \mathrm{kcal} / \mathrm{mol} & \Delta \mathrm{E}_{1}(585)=66.5 \quad \Delta \mathrm{E}_{1}(545)=64.3 \\
\Delta \mathrm{E}_{1}(600) & =66.0 & \Delta \mathrm{E}_{1}(565)=65.8 &
\end{array}
$$

In general, the theoretical curves fit the data very well and describe accurately the viscosity change as a function of time. The mixed state viscosity, $\eta(T, 0)$ deviated slightly from the assumed Arrhenian behavior (Eq. 12) in samples of the Type I glass (see fig. 18), therefore, the value of $1 \mathrm{n} \eta_{0}$ varied \pm 0.4 in order to fit the data. The small variation in $\Delta \mathrm{E}_{1}$ from $620^{\circ} \mathrm{C}$ to $560^{\circ} \mathrm{C}$ in the Type I samples is probably experimental uncertainty since in a11 cases we have measurements where $f(\Lambda)$ has approached its saturation region. At $540^{\circ} \mathrm{C}$, however, the lower value of $15.6 \mathrm{kcal} / \mathrm{mol}$ is probably due to a yet incomplete phase separation. The activation energy for flow in the viscous phase is $146 \mathrm{kcal} / \mathrm{mol}\left[E_{1}=E_{0}+\Delta E_{1}\right]$. As in reference 7 , the activation entropy $\Delta \mathrm{S}_{1}$ is negligible. 


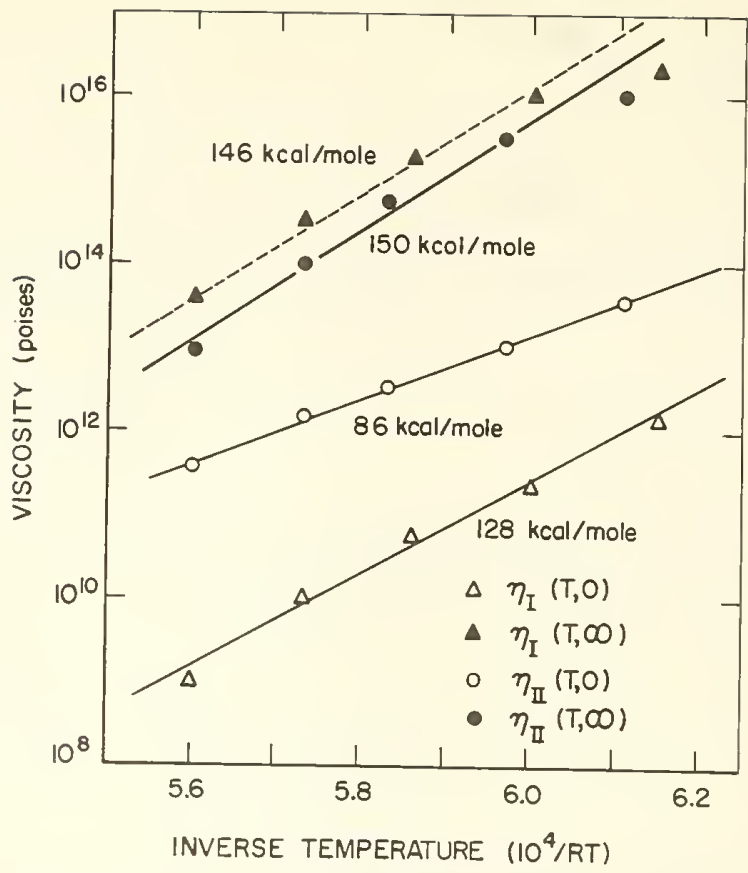

Fig. 18. Plots of the mixed-state viscosity, $n(T, O)$, and the totally-separated viscosity, $\eta(T, \infty)$, as a function of inverse temperature for both glasses.

In samples of the Type II glass, the mixed state viscosity, n(T,o), is Arrhenian (see fig. 18). In this glass, however, there is a sizeable activation entropy. Fitting the data without it required temperature dependent values for $\Delta \mathrm{E}_{1}$, and values too small to be physically meaningful. With an activation entropy, we have an excellent fit of the data, and the value of $\Delta \mathrm{E}_{1}$ at $66 \mathrm{kcal} / \mathrm{mol}$ yields an activation energy of $150 \mathrm{kcal} / \mathrm{mol}$ for the more viscous (high $\mathrm{SiO}_{2}$ ) phase. This compares well to the activation energy for viscous flow in pure $\mathrm{SiO}_{2}$ [20]. 
We have presented viscosity measurements conducted on two glasses with similar compositions but different immiscibility behavior. Both glasses are basically soda-borosilicates. The first (Type I) is a "model" composition for immiscibility studies. Its phase transition occurs near the maximum of the immiscibility surface for the system. Therefore, the transition is easily observed and phase separation occurs quickly. The phases have equal volume fractions, and exhibit a marked difference in chemical durability. The second glass (Type II) is widely used for chemical glassware, and its transition is difficult to detect. The glass contains more silica and less soda than Type I, and $2 \%$ alumina. The composition is located in the narrowing portion of the immiscibility dome, and the transition temperature is approximately $100^{\circ} \mathrm{C}$ below that of Type I.

The viscosity measurements were made below the phase transition temperature of each glass in order to investigate the effect of microstructure growth on the viscous flow processes. The viscosity increased by 4 to 5 orders of magnitude as a function of heat-treatment time (ranging to $100,000 \mathrm{~min}$. ) at a fixed temperature.

An analysis of the microstructure development with electron microscopy of replicated, etched surfaces, showed that an increase in microstructure size was primarily responsible for the viscosity increase. This growth followed a $1 / 3$ power of time suggesting the rearrangement stage of phase separation. An analysis of the growth rate at different temperatures yields an activation energy for the regarrangement process which is probably occurring by bulk diffusion of silica through the fluid phase. This was $97 \mathrm{kcal} / \mathrm{mol}$ for the Type I and $70 \mathrm{kcal} / \mathrm{mol}$ for the Type II glass. The low activation energy for Type II was coupled with a very small pre-exponential term indicating the effect of an activation entropy. The latter explains the observed slow microstructure growth. The difference in growth rates between the glasses is as expected, since the fluid phase of Type I contains less silica. Also expected is the value of $97 \mathrm{kcal} / \mathrm{mol}$ for the activation energy for 
bulk diffusion in the fluid phase of Type I. The value of $70 \mathrm{kcal} / \mathrm{mol}$ for Type II is surprisingly low. This is not due to a possible different rate-controlling mechanism for rearrangement since they would all exhibit a higher energy than bulk diffusion. It has been suggested that the tie lines in this system run approximately parallel to the $\mathrm{Na}_{2} \mathrm{O}-\mathrm{SiO}_{2}$ boundary [19], therefore, the fluid phases of Types I and II contain approximately equal amounts of sodium oxide (see points 35 and 42 in fig. 1 of Ref. 8 for comparison). It appears that the change in $\mathrm{B}_{2} \mathrm{O}_{3}$ affects the pre-exponential term (possibly through the activation entropy). It is interesting to note finally, that while the measurements were conducted in the same viscosity range for both glasses, the structure of Type I developed faster than Type II because of the change in the pre-exponential term.

A model relating a change in viscosity to a change in microstructure size through the distribution of activation energies was modified to apply to subcritical microstructure growth. The resulting equation was fitted to the data with excellent quantitative results. The parameters from the fit yield the mixed-state viscosity, the viscosity of the silica-rich phase, and the range of molecular influence for viscous flow in the liquid. The mixed-state viscosities for both glasses follow we11 the data measured above the transition temperature (see fig. 1). Curiously again, the Type II glass has a lower activation energy than Type I despite their composition differences, indicating that the preexponential terms in the rate equation dominate in this temperature range. The change in viscosity resulting from phase separation is smaller in Type II as expected, since the change in composition is less due to a narrowing of the immiscibility dome (see Ref. 8). This narrowing also accounts for the small difference in chemical durability observed in Type II when leaching during sample preparation for electron microscopy. The activation energy for diffusion in the viscous phase of Type I is $146 \mathrm{kcal} / \mathrm{mol}$, which is within the range of values reported for silica [20]. Type II shows $150 \mathrm{kcal} / \mathrm{mol}$ which is also close to silica, and is a reasonable value since its viscous phase is primarily composed 
of $\mathrm{SiO}_{2}$ and $\mathrm{Al}_{2} \mathrm{O}_{3}{ }^{*}$ *

Finally, in comparing the value of $r_{0}$, the range of molecular influence for viscous flow, between the two glasses, we obtain excellent consistency with 57 and $58 \AA$ for Types $I$ and II, respectively. This also agrees well with a value obtained for the Type I glass (41-56\&) by ultrasonic relaxation spectroscopy far above the transition temperature $\left(800-1200^{\circ} \mathrm{C}\right)$. This parameter defines the extent of the local environment around the flow species or molecules and the shape of the viscosity curve in terms of microstructure size is sensitive to its value. The consistency obtained here along with the excellent quantitative fits of the data supports the application of the model to this process.

In closing, we find that there is a large effect of subcritical microstructure growth on the viscosity of glass. As shown in figure 11f, this effect is complex and will strongly affect stress release in the glass due to the time-dependent viscosity increase. The effect can be quantitatively described in terms of a model presented here. Values of the parameters used in the model appear to support the physical significance assigned to them during the development of the model. Application of the model only depends upon the activation enthalpy differences and the size of the structure. This, therefore, facilitates its use on microstructure development in materials, arising from causes other than immiscibility.

* Chemical analysis of a similar glass phase-separated and leached at this laboratory indicated that all the $\mathrm{Al}_{2} \mathrm{O}_{3}$ remained in the phase rich in silica. 


\section{References}

[1] J. Konnert, J. Karle and G. A. Ferguson, Bul. Am. Ceram. Soc. 51, 374 (1972).

[2] A. Napolitano and P. B. Macedo, J. Res. Nat. Bur. Stand. (U.S.) 72A, 425 (1968).

[3] J. Zarzycki and R. Mezard, Phys. Chem. Glasses 3 (5), 163 (1962).

[4] E. A. Porai-Koshits, V. I. Averjanov, N. S. Andreev and

V. V. Golubkov, IX International Congress on Glass 1, 391 (1971).

[5] T. P. Seward, III and D. R. Uhlmann, Amorphous Materials,

R. W. Douglas and B. Ellis, Eds. (John Wiley \& Sons, London, 1972) p. 327 .

[6] W. Vogel, Silikattechn. 9, 51 (1958); ibid. 10, 241 (1959);

T. H. Elmer, M. E. Nordberg, G. B. Carrier and E. J. Korda,

J. Amer. Ceram. Soc. 53, 171 (1970) .

[7] J.H. Simmons and P. B. Macedo, J. Res. Nat. Bur. Stand. (U.S.) 75A, 175 (1971).

[8] W. Haller, D. H. Blackburn, F. E. Wagstaff and R. J. Charles, J. Amer. Ceram. Soc. 53, 34 (1970).

[9] J. H. Simmons, A. Napolitano and P. B. Macedo, J. Chem. Phys. 53, 1165 (1970).

[10] J. H. Simmons and P. B. Macedo, J. Chem. Phys. 53, 2914 (1970); ibid 54, 1325 (1971).

[11] J. H. Simmons, P. B. Macedo, A. Napolitano and W. Haller, Discussions of the Faraday Society 50, 155 (1970).

[12] W. Haller, J. Chem. Phys. 42, 686 (1965).

[13] R. Mahoney, G. R. Srinivasan, P. B. Macedo, A. Napolitano and J. H. Simmons, Phys. Chem. Glasses, submitted.

[14] H. Bach, J. Non-Crystalline Solids 3 , 1 (1970).

[15] P. F. James and P. W. MacMillan, Phys. Chem. Glasses 11, 59 (1970).

[16] A. Napolitano and E. G. Hawkins, J. Res. Nat. Bur. of Stand. (U.S.) $68 \mathrm{~A}, 439$ (1964).

[17] B. F. Howell, J. H. Simmons and W. Haller, "Chemical Durability Deterioration of a Phase-Separated Glass," in preparation. 
[18] J. Zarzycki and F. Naudin, J. Non-Crystalline Solids 1 , 215 (1969).

[19] O. V. Mazurin, V. P. Kluyev and G. P. Roskova, Phys. Chem. Glasses 11, 192 (1970).

[20] G. Hofmaier and G. Urbain, Science of Ceramics 4, 25 (1968). 

$=O F M$ NBS.114A (1.71)

U.S. DEPT. OF COMM.

BIBLIOGRAPHIC DATA

SHEE T

1. PUBLICATION OR REPORT NO. NBS TN -792
2. Gov't Accession No.

4. TITLE AND SUBTITLE

Investigation of Viscous Flow in Glass During Phase Separation

7. AUTHOR(S) J. H. Simmons, S. A. Mills, A. Napolitano

D. H. Blackburn, W. K. Haller

9. PERFORMING ORGANIZATION NAME AND ADDRESC

NATIONAL BUREAU OF STANDARDS

DEPARTMENT OF COMMERCE

WASHINGTON, D.C. 20234

12. Sponsoring Organization Name and Address

Office of Naval Research

Department of the Navy

Code 471

Washington, D.C. 20360

15. SUPPLEMENTARY NOTES

16. ABSTRACT ( A 200-word or less factual summary of most significant information. If document includes a significant bibliography or literature survey, mention it here.)

The isothermal viscosity of two borosilicate glasses, of which one is a conmercial glass widely used for chemical glassware, shows a large increase ( 4 to 5 orders of magnitude) with heat-treatment time (ranging up to 100,000 min) near the annealing point. The two glasses have similar compositions, but differ greatly in their phase separation characteristics. Electron micrographs are used to analyze the development of microstructure during the suspected phase separation. In both glasses, it is found that the structure development is primarily responsible for the viscosity increase. An analysis of the data, and a theoretical interpretation of the effect are presented.

17. KEY WORDS (Alphabetical order, separated by semicolons)

Glass; microstructure; phase separation; viscosity.

18. AVAILABILITY STATEMENT

UNLIMITED.

FOR OFFICIAL DISTRIBUTION. DO NOT RELEASE TO NTIS.

\begin{tabular}{|c|c|}
\hline $\begin{array}{l}\text { 19. SECURITY CLASS } \\
\text { (THIS REPORT) }\end{array}$ & 21. NO. OF PAGES \\
\hline UNCL ASSIFIED & 43 \\
\hline $\begin{array}{l}\text { 20. SECUR ITY CLASS } \\
\text { (THIS P AGE) } \\
\text { UNCL ASSIFIED }\end{array}$ & $\begin{array}{l}\text { 22. Price } \\
\$ 0.65\end{array}$ \\
\hline
\end{tabular}





\section{NBS TECHNICAL PUBLICATIONS}

PERIODICALS

JOURNAL OF RESEARCH reports National Bureau of Standards research and development in physics, mathematics, and chemistry. Comprehensive scientific papers give complete details of the work, including laboratory data, experimental procedures, and theoretical and mathematical analyses. Illustrated with photographs, drawings, and charts. Includes listings of other NBS papers as issued.

Published in two sections, available separately:

\section{- Physics and Chemistry (Section A)}

Papers of interest primarily to scientists working in these fields. This section covers a broad range of physical and chemical research, with major emphasis on standards of physical measurement, fundamental constants, and properties of matter. Issued six times a year. Annual subscription: Domestic, $\$ 17.00$; Foreign, \$21.25.

\section{- Mathematical Sciences (Section B)}

Studies and compilations designed mainly for the mathematician and theoretical physicist. Topics in mathematical statistics, theory of experiment design, numerical analysis, theoretical physics and chemistry, logical design and programming of computers and computer systems. Short numerical tables. Issued quarterly. Annual subscription: Domestic, $\$ 9.00$; Foreign, $\$ 11.25$

\section{TECHNICAL NEWS BULLETIN}

The best single source of information concerning the Bureau's measurement, research, developmental, cooperative, and publication activities, this monthly publication is designed for the industry-oriented individual whose daily work involves intimate contact with science and technology-for engineers, chemists, physicists, research managers, product-development managers, and company executives. Includes listing of all NBS papers as issued. Annual subscription: Domestic, $\$ 6.50$; Foreign, $\$ 8.25$.

\section{MOAPERIODICALS}

Applied Mathematics Series. Mathematical tables, manuals, and studies.

Building Science Series. Research results, test methods, and performance criteria of building materials, components, systems, and structures.

Handbooks. Recommended codes of engineering and industrial practice (including safety codes) developed in cooperation with interested industries, professional organizations, and regulatory bodies.

Special Publications. Proceedings of NBS conferences, bibliographies, annual reports, wall charts, pamphlets, etc.

Monographs. Major contributions to the technical literature on various subjects related to the Bureau's scientific and technical activities.

National Standard Reference Data Series. NSRDS provides quantitative data on the physical and chemical properties of materials, compiled from the world's literature and critically evaluated.

Product Standards. Provide requirements for sizes, types, quality, and methods for testing various industrial products. These standards are developed cooperatively with interested Government and industry groups and provide the basis for common understanding of product characteristics for both buyers and sellers. Their use is voluntary.

Technical Notes. This series consists of communications and reports (covering both other-agency and NBS-sponsored work) of limited or transitory interest.

Federal Information Processing Standards Publications. This series is the official publication within the Federal Government for information on standards adopted and promulgated under the Public Law 89-306, and Bureau of the Budget Circular A-86 entitled, Standardization of Data Elements and Codes in Data Systems.

Consumer Information Series. Practical information, based on NBS research and experience, covering areas of interest to the consumer. Easily understandable language and illustrations provide useful background knowledge for shopping in today's technological marketplace.

\section{BIBLIOGRAPHIC SUBSCRIPTION SERVICES}

The following current-awareness and literature-survey bibliographies are issued periodically by the Bureau:

Cryogenic Data Center Current Awareness Service (Publications and Reports of Interest in Cryogenics). A literature survey issued weekly. Annual subscription: Domestic, $\$ 20.00$; foreign, $\$ 25.00$.

Liquefied Natural Gas. A literature survey issued quarterly. Annual subscription: \$20.00.

Superconducting Devices and Materials. A literature survey issued quarterly. Annual subscription: $\$ 20.00$ Send subscription orders and remittances for the preceding bibliographic services to the U.S. Department of Commerce, National Technical Information Service, Springfield, Va. 22151.

Electromagnetic Metrology Current Awareness Service (Abstracts of Selected Articles on Measurement Techniques and Standards of Electromagnetic Quantities from D-C to Millimeter-Wave Frequencies). Issued monthly. Annual subscription: $\$ 100.00$ (Special rates for multi-subscriptions). Send subscription order and remittance to the Electromagnetic Metrology Information Center, Electromagnetics Division, National Bureau of Standards, Boulder, Colo. 80302.

Order NBS publications (except Bibliographic Subscription Services) from: Superintendent of Documents, Government Printing Office, Washington, D.C. 20402. 
U.S. OEPARTMENT OF COMMERCE

National Bureau of Standards

Washington, D.C. 20234

POSTAGE ANO FEES PAID

OFFIGIAL BUSINESS

U.S. DEPAATMENT OF COMMERCE COM-2\$5

Penalty for Private Use. \$300 


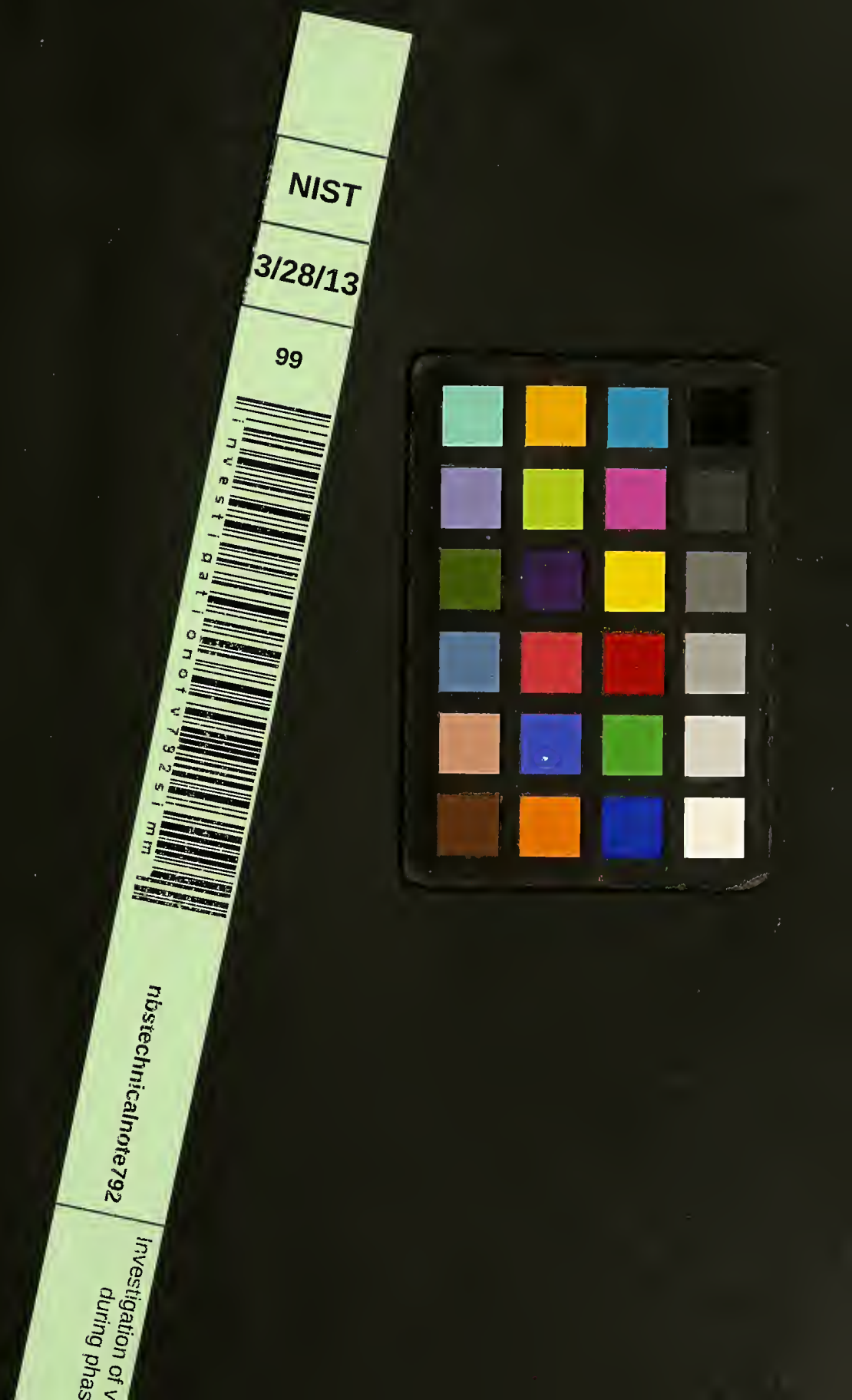



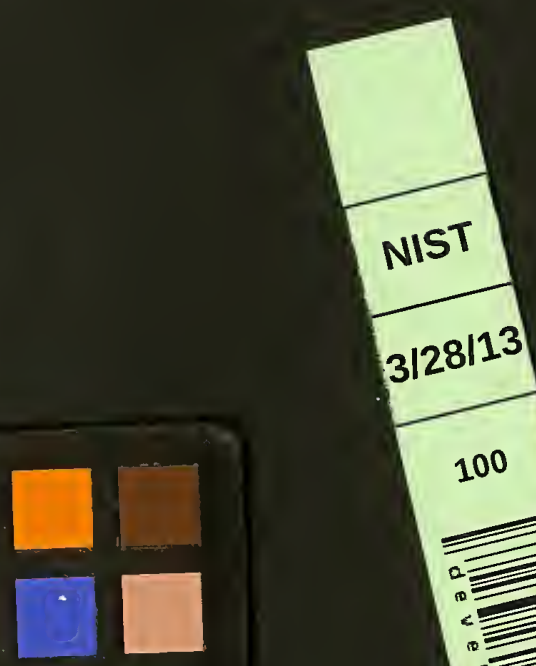

\section{3}

100
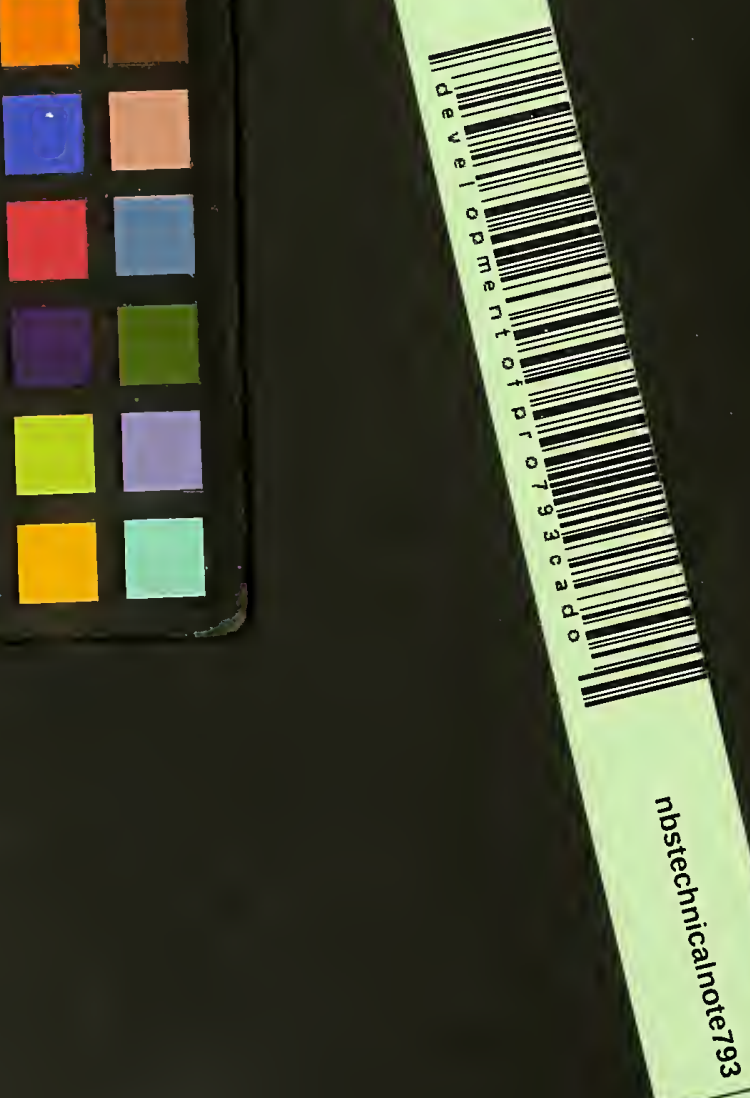

30

\&

ก

政 